\title{
Los incoterms como instrumento de derecho suave (soft law) ${ }^{1}$
}

\section{The incoterms as an instrument of soft law}

\author{
EduARdo CALderón MARENCO²
}

\section{RESUMEN}

Derivado de las profundas transformaciones que ha experimentado el Derecho internacional, la Lex Mercatoria y el Derecho suave (Soft law) han emergido como una alternativa al tradicional Derecho duro (Hard law). Con el paso del tiempo el Derecho suave (Soft law) ha ido adquiriendo un mayor protagonismo en el escenario jurídico internacional, posicionándose como un instrumento del que gozan las partes para regular sus transacciones internacionales, aunque carezca de efectos vinculantes. No obstante se encuentra revestido de voluntariedad, por medio de la autonomía conflictual, lo que les otorga un carácter vinculante para las partes. Es así que este Derecho se compone de un amplio espectro de instrumentos, los que encuentran aceptación en los diferentes sistemas jurídicos, en variadas áreas del derecho, y dan respuesta a las necesidades de los diferentes interesados. Empero, en el ámbito comercial internacional estos instrumentos se han nutrido de la Lex Mercatoria, un ejemplo de ello son los Incoterms, usos y costumbres que uniforman y sistematizan este ordenamiento jurídico, creado por los comerciantes, propio de los negocios jurídicos de compraventa internacional de mercadería. Por esto consideramos relevante analizar esta nueva corriente a nivel internacional y su incorporación dinámica en estos instrumentos jurídicos.

1 Fecha de recepción: 19 de abril de 2018. Fecha de aceptación: 27 de junio de 2018. Para citar el artículo: Calderón E. "Los incoterms como instrumento de derecho suave (soft law)". En Revist@ E-Mercatoria, vol.17,n. ${ }^{\circ}$ 1, enero-junio, 2018. DOI: https://doi. org/10.18601/16923960.v17n1.02

2 El autor es Maestro en Derecho de los Negocios Internacionales por la Universidad Iberoamericana de México. Investigación realizada en el marco del Programa de Doctorado "Cuestiones actuales del Derecho" 2 da edición de la Universidad Centroamericana, Nicaragua. eduardo.calderon.marenco@gmail.com 
Palabras claves: Lex Mercatoria / Incoterms / Autonomía Conflictual / Derecho suave / Derecho duro.

\section{ABSTRACT}

Derived from the profound changes that international law has undergone, the Lex Mercatoria and the Soft Law have emerged as an alternative to the traditional Hard Law. With the passage of time, the Soft Law has been acquiring a greater role in the international legal scene, positioning itself as an instrument enjoyed by the parties to regulate their international transactions, although it lacks binding effects. However, it is covered with voluntariness, through conflict autonomy, which gives them a binding character for the parties. Thus, this Law is composed of a broad spectrum of instruments, which find acceptance in different legal systems, in various areas of law, and respond to the needs of different stakeholders. However, in the international commercial field these instruments have been nurtured by the Lex Mercatoria, an example of which are the Incoterms, uses and customs that standardize and systematize this legal system, created by the merchants, typical of the legal business of international sales of commodity. For this reason, we consider it important to analyze this new international trend and its dynamic incorporation in these legal instruments.

Keywords: Lex Mercatoria / Incoterms / Conflict Autonomy / Soft Law / Hard Law

\section{INTRODUCCIÓN}

Una de las áreas del Derecho mayormente influenciada por la globalización ha sido el Derecho mercantil internacional, ligado directamente por la evolución de las tecnologías, las aperturas económicas, y el incremento de intercambio de bienes y servicios trasfronterizo, lo que ha implicado la adecuación del Derecho a estas nuevas tendencias. Transfigurando así la idea clásica de la producción de normas sustantivas únicamente a manos de los Estados, quedando en entredicho su omnipresente intervención, debido a la creciente complejidad de la sociedad de comerciantes, lo que a su vez ha evidenciado la falta de capacidad de la norma imperativa para resolver la totalidad de los conflictos de intereses que se producen en el entorno del comercio internacional.

Ante esta necesidad, ha tomado nuevamente auge la Lex Mercatoria, como Derecho creado por los comerciantes con el objetivo de evitar la aplicación de normas estatales. En este mismo plano surge otra realidad normativa en el plano internacional, denominada Derecho suave (Soft law), que se integra a la búsqueda de soluciones sobre esta problemática, lo que ha permitido la 
puesta en escena de nuevos sujetos distintos de los Estados, tales como organizaciones internacionales, comunidades supranacionales o regionales, entre otros, las que han configurado una serie de instrumentos que se caracterizan por carecer de efectos vinculantes, es decir no son obligatorios, por lo que se denominan instrumentos de Derecho suave (Soft law). No obstante, muchos de estos instrumentos en el espacio del comercio internacional se han elaborado en base a la Lex Mercatoria. Con todo, esta noción no ha estado carente de discusiones y confusiones, dado que ambos términos no deben de entenderse como sinónimos.

Ambas realidades, tanto la Lex Mercatoria como el Derecho suave (Soft law), gozan de gran preferencia entre los comerciantes por la libertad y flexibilidad que otorgan a los sujetos al brindarles la oportunidad de elección de un Derecho distinto a las legislaciones nacionales, un ejemplo de estos son los Incoterms. Por tal razón, a continuación haremos un estudio pormenorizado de estos términos: Derecho suave (Soft law) y Lex Mercatoria.

\section{EL DERECHO SUAVE (SOFT LAW)}

Al pasar por las líneas investigativas del Derecho comercial internacional es innegable hablar de los cambios surgidos por la vorágine que representa la globalización en todos los aspectos del ser humano, la sociedad y el Estado. De tal suerte que el Derecho no escapa de su influencia y, mucho menos, esta materia específica. De manera más puntual, y en sintonía con esta investigación, debemos anotar que para el comercio transnacional la idea de la creación del Derecho aplicable e imperativo únicamente por los órganos estatales, ya no es una realidad tan material, más aun en el ámbito internacional donde confluyen con rapidez las transacciones comerciales, y cobran vida las propias regulaciones elaboradas por los comerciantes a raíz de la autonomía de la voluntad. Lo que permite la creación de un Derecho paralelo al Derecho creado por los Estados, sin embargo no con el carácter vinculante que imprime este último, pero si considerado una fuerte y sólida base que sustenta la existencia de un ordenamiento jurídico instaurado por este sector social, denominado: Lex Mercatoria.

Y es que, a la par de este Derecho de raíz consuetudinaria, también contraponemos el plano real que ofrece la subsistencia de diversidad normativa en espacios económicos transnacionales cada vez más integrados, que invitan al comerciante a seleccionar el Derecho aplicable en las contrataciones internacionales. Esta determinación puede ser obra de la voluntad (autonomía conflictual) de los contratantes, escogiendo una norma imperativa de Derecho nacional o bien emanados de la Lex Mercatoria. Todo lo anterior con el ánimo de satisfacer los intereses de los mismos (contratantes) y brindar la seguridad jurídica que en muchas ocasiones no otorgan las legislaciones nacionales por no ser acordes al contexto de este tipo de transacciones (Bouza Vidal, 2005). 
Ruiz Castellanos (2016) refiere que la globalización de los mercados reclama una regulación uniforme de los tráficos internacionales, solicitando una nueva universalidad del Derecho. Por esta razón el dinamismo del comercio internacional y su particular regulación, a la vez que ha permitido la creación un nuevo ordenamiento jurídico (Lex Mercatoria), ha dado pautas para el nacimiento de nuevas figuras y montajes contractuales, convenios internacionales, actos de instituciones internacionales a las que los Estados han transferido competencias en la materia, y la creación de normas por parte de los propios operadores jurídicos y económicos que participan en el comercio internacional, cuestión de la que ya hemos hecho mención. Es por tanto que muchas normativas uniformes desarrolladas al amparo de Lex Mercatoria, y que se han perfeccionado en el mercado global, explican el favor que gozan estos mecanismos de regulación considerados más ajustados a las exigencias de la misma globalización y particulares (comerciantes).

Estas normas se han denominado Derecho suave (Soft Law), las cuales presentan una problemática específica, y es que su reconocimiento se contrasta con la vinculación y efecto jurídico que producen en los ordenamientos legales nacionales (Hard Law). El Derecho suave (Soft Law) en materia comercial se ha desarrollado y nutrido a partir de la Lex Mercatoria, por lo que para afrontar el tratamiento de esta problemática y sus posibles soluciones, consideramos propicio construir los aspectos generales más relevantes: desde la conceptualización, pasando por su naturaleza jurídica, hasta su vinculación y limitantes con los Derechos nacionales.

\section{ASPECTOS GENERALES}

Antes de descifrar la naturaleza jurídica del Derecho suave (Soft Law), otorgamos plena importancia a los aspectos generales de carácter histórico que dieron nacimiento a este nuevo orden normativo de carácter internacional. Y es que la omnipresente intervención del Estado no resulta materialmente efectiva debido a la creciente complejidad de la sociedad de comerciantes y a la consiguiente dificultad para que la intervención normativa resuelva la totalidad de los conflictos de intereses, razón por la que se han incorporado a la escena de los negocios internacionales nuevos sujetos distintos de los Estados, tales como organizaciones internacionales, comunidades supranacionales o regionales, empresas multinacionales y organizaciones no gubernamentales, las cuales desempeñan distintos roles que influyen decididamente en el ámbito jurídico internacional (Cortes Cabrera, 2014).

Como bien ilustra Cortes Cabrera (2014) la doctrina reconoce que el término de Derecho suave (Soft Law) fue acuñado por Lord Arnold McNair de la escuela británica de leyes y el primer presidente de la Corte Europea de Derechos Humanos, pero este concepto cuenta con diversas interpretaciones, de forma tal que hasta el día de hoy podríamos decir que encontrar un concepto 
unívoco de este Derecho es tarea titánica. Empero, apuntamos que principalmente esta noción se ha atribuido para distinguir entre proposiciones lege ferenda y lege data. De manera más concreta la autora, precitada, considera que con la expresión Soft law se intentan describir enunciados formulados como principios abstractos y presentes en todo ordenamiento, y provenientes de su aplicación judicial, sin embargo en el contexto actual agregaría que también son provenientes de su aplicación en sedes arbitrales, aseveración que desarrollaremos en los apartados posteriores de este artículo.

En 1983, Prosper Weil publicó "Towards relative normativity in international law", y Weil utilizaba el término Soft law para caracterizar algunas normas que no son legalmente vinculantes. Pese al transcurso de los años y de los intentos fallidos por conceptualizarlo, la doctrina no ha logrado consolidar un solo significado, tal como declaramos con anterioridad. En estos mismos trazos argumentativos, Mazuelos Bellido (2004) nos ilustra que la expresión Soft law (Derecho suave) ha sido utilizada en relación con diferentes realidades del Derecho. No obstante la locución trataba de representar enunciados normativos que devenían operativos a través de su aplicación judicial, así como lo refirió Cortes Cabrera (2014), por tanto, es así que en su origen, el Soft law no describía una realidad existente únicamente en el ordenamiento jurídico internacional, pero ha sido en esta disciplina donde el término fue acogido doctrinalmente y en el que ha dado lugar a amplias discusiones. De estas afirmaciones también es participe Boretto (2012), quien alude que en su origen la expresión no estaba asociada exclusivamente al plano internacional, pero su fundamento dogmático se lo debe a este ámbito.

Uno de los objetivos de este artículo es indagar sobre sus distintas acepciones y reflexionar acerca de su utilidad y pertinencia en el Derecho del comercio internacional. A continuación examinaremos los diferentes significados del Derecho suave (Soft Law) con el ánimo de establecer su naturaleza jurídica y entramar nuestra propia tesitura en relación a su parte conceptual.

\section{CONCEPTO Y NATURALEZA JURÍDICA}

Resulta usual utilizar la denominación de Derecho suave (Soft Law) para referirse a todos aquellos actos que carecen de eficacia normativa y que son dictados por organismos internacionales. Snyder, citado por Galiana Saura (2016), refiere que sin importar que estos actos tengan poder normativo o carezcan de él, con diversa denominación como resoluciones, recomendaciones, guías, códigos o estándares de conducta, se trata de normas que carecen de eficacia directa y erga omnes, así como de la oponibilidad propia de las normas jurídicas de Derecho imperativo de los Estados (Hard Law).

Por otra parte, para Sarmiento (2006): 
El Derecho suave, o débil, siempre ha estado presente en los sistemas jurídicos; incluso el Derecho romano conceptualizaba estas formas de regulación como leges imperfecta. Pero el soft law, tal como lo conocemos en la actualidad, es una criatura del Derecho Internacional y, en especial, de las organizaciones internacionales, cuyas normas no siempre gozan de efectos jurídicos nítidos (p. 224).

Esta misma posición la comparte Galiana Saura (2016), para ella, el Derecho suave (Soft law) se refiere a reglas de conducta que se encuentran en el nivel de lo no vinculante jurídicamente pero que, de acuerdo con la intención de sus autores, posee un alcance jurídico que ha de ser definido ulteriormente en cada caso. Es por esto que podemos decir que tales reglas no tienen en común un estándar de intensidad uniforme por lo que a su alcance jurídico respecta.

Otro concepto que traemos a colación es el vertido por Del Toro Huerta (2006) quien expone que el término es usualmente empleado para describir principios, reglas, estándares o directrices que carecen de efecto vinculante aunque no dejan por ello de producir determinados efectos jurídicos, este tipo de normativa suele representarse en documentos internacionales de resoluciones de organizaciones internacionales, recomendaciones e informes adoptados por organismos internacionales o dentro de conferencias internacionales programas de acción; textos de tratados que no han entrado en vigor, declaraciones interpretativas de determinados tratados o convenios; disposiciones programáticas o non-self-executing; acuerdos no normativos, acuerdos políticos o gentlemen's agreement, códigos de conducta, directrices, estándares, etc.

Como bien podemos observar, la diversidad de instrumentos internacionales que suelen enmarcarse dentro del denominado Derecho Suave (Soft law) hacen de éste un concepto demasiado amplio para dotarlo de un sentido único en el discurso del Derecho internacional; tal parece que su característica principal se refiere a sus efectos no obligatorios. Así mismo apuntan Guzmán y Meyer, citados por Cortes Cabrera (2014), que este término se entiende como un continuo, o espectro, que se mueve entre tratados completamente vinculantes y posturas netamente políticas que carecen de esta vinculación jurídica. Se suma a estos argumentos Fernández Rozas (2010) y agrega que a pesar de su carácter (no vinculante) el Derecho Suave (Soft law) ejerce una influencia decisiva en la voluntad de los operadores jurídicos, incluyendo a comerciantes, árbitros y órganos jurisdiccionales nacionales. Por consiguiente es una concepción particularmente operativa en el Derecho internacional tanto para el desarrollo legislativo futuro, o bien como referentes específicos

Pues bien, para finalizar estos aportes doctrinarios consideramos que el concepto brindado por González Rivera \& Castrillón y Luna (2015) es el más preciso, ellos conciben al Soft Law como instrumentos, ciertamente escritos, que si bien derivan de una práctica deben plasmarse en documentos con categoría internacional, los cuales denotan lo no obligatorio (elementos que enuncian la mayoría de doctrinarios). Además, dejan en evidencia que se trata de normas 
aspiracionales impulsadas sobre manera por los organismos internacionales, vistos como nuevos sujetos del entorno mundial.

Después de analizar estas posturas científicas, para nosotros, Derecho Suave (Soft law) debe entenderse como el conjunto de instrumentos normativos emanados por organismos o instituciones internacionales que especialmente se determinan por carecer del efecto vinculante que tiene las normas de Derecho imperativo pero sin restarle efecto jurídico, por configurar un nuevo orden de Derecho proveniente del ámbito internacional, así mismo serán considerados instrumentos de Derecho suave (Soft law), todos aquellos que se han materializado normativamente pero que no se han incorporado al Derecho nacional, verbigracia, los tratados internacionales multilaterales que no han sido integrados al Derecho imperativo estatal.

A partir de lo anterior, podemos estructurar la naturaleza jurídica y sus características relevantes. Y es que, el Soft law es una evidencia de la adaptación del Derecho a un nuevo contexto global, puesto que la realidad reclama con ímpetu efectividad inmediata y activismo en su adaptabilidad al nuevo entorno, pero con mayor empeño en el plano comercial internacional. Aunque debemos acotar que el Derecho suave (Soft law) no está pensado únicamente para su aplicación en este ámbito (comercial).

En este nuevo escenario cobra fortaleza el paradigma liberal de la autonomía de la voluntad, en sus dos formas: material y conflictual, por lo que permite a las partes transformar sus realidades contractuales, las cuales pueden estar apegadas tanto a las normas imperativas que crea el Estado, o bien, a instrumentos de Soft law, constituyéndose como una fuente alternativa. Por ende su naturaleza es meramente dispositiva (Cortes Cabrera, 2014) caracterizada por su falta de coercitividad, desapego a la rigidez del principio de legalidad e indeterminada en su contenido.

Boretto (2012) explica que Derecho Suave (Soft law) posee una naturaleza constituida por reglas y principios, estos últimos -los principios- son mandatos de optimización, de contenido determinado en su antecedente, pero indeterminado en sus consecuencias, pero lo más importante es que siempre se van a caracterizar por la ausencia de efectos vinculantes. No obstante, cabe señalar que esto no implica la ausencia de efectos jurídicos (Galiana Saura, 2016), ya que como indicaremos posteriormente, el Derecho Suave (Soft law) puede tener vinculaciones directas con el Derecho sustantivo.

Categóricamente estamos en presencia de una clase de Derecho emanado de organismos transnacionales alejados de la realidad típica del nacimiento de la norma imperativa por parte de órganos estatales. En consecuencia, engloba fenómenos heterogéneos donde concurre un mínimo denominador, la falta de obligatoriedad jurídica, en otras ocasiones la falta de juridicidad, y la relevancia jurídica. En síntesis, Mazuelos Bellido (2004) expresa: "el Soft law se caracteriza por ser un instrumento jurídicamente no vinculante y poseer cierta relevancia jurídica, siendo su espacio natural de producción el derecho 
internacional" (p. 84). Es decir que es un fenómeno jurídico derivado de los procesos de internacionalización de las distintas ramas y parcelas del Derecho, es una manera flexible y ágil de crear un tipo de instrumentos normativos internacionales carente de fuerza coercitiva, pero no por ello de validez y legitimidad (González Rivera \& Castrillón y Luna, 2015).

Por tanto, nosotros entendemos que la naturaleza jurídica del Derecho Suave (Soft law), es dispositiva, siendo que son instrumentos flexibles y no obligatorios para los particulares y los Estados, a menos que cobre efectos vinculantes mediante la autonomía de la voluntad en las contrataciones internacionales, o bien, sean fuente de Derecho para las legislaciones nacionales en donde el órgano legislativo estatal tenga a bien incorporarlos materialmente en un cuerpo legal. En tanto, hay que volver a poner de manifiesto que no hay unanimidad acerca de la expresión y por ello resulta necesario definir previamente el término cuando se vaya a emplear, dependiendo en muchas ocasiones de la materia del Derecho donde se manifieste. A este respecto, las normas de Derecho suave (Soft law), enfrentan al modelo dicotómico tradicional o bien conocido como Derecho duro (Hard law) (Medina González, 2016), de tal manera podemos advertir que la influencia de estas normas (Derecho suave), de carácter flexible, pueden devenir en la creación o interpretación de normas imperativas, vinculándose directamente estos dos contextos, por lo que en el siguiente apartado atenderemos lo pertinente a esta temática.

\section{Dicotomía entre Derecho Suave (Soft LaW) y DERECHO DURO (HARD LAW)}

Exponer la dicotomía entre el Derecho Suave (Soft Law) y Derecho Duro (Hard law), es plasmar los argumentos que respalda la separación de ambos ordenamientos ${ }_{i}$ sin embargo esta separación en ciertos ámbitos del Derecho debe ser reducida a la mínima expresión, sobre todo en la realidad material del comercio internacional. Empero, para entender esta aseveración es necesario comprender los aspectos fundamentales de la doctrina que atribuyen el carácter dicotómico a ambos tipos de normas. Antes de continuar con este análisis definamos Hard law como una regla emanada de una autoridad legislativa que sí cumple con las formalidades constitucionales y, de otra índole, que sean necesarias para que la norma sea jurídicamente vinculante.

Para Medina González (2016) a este respecto surge una dicotomía jurídica, en donde el Derecho suave (Soft law) se puede reconocer porque contrasta con las reglas legales que definen obligaciones específicas de Derecho duro (Hard law), es decir, estas normas inspiradas en principios más abiertos o generales en su contenido y significado, comprendiéndose como suaves en lo concerniente a su aplicación. Y es que Alarcón, citado por Medina González (2016), enuncia que debido a la dinámica que impone el Derecho internacional es difícil observar un concepto tradicional de ordenamiento jurídico en el que 
exclusivamente las normas producidas por las fuentes jurídicas tradicionales (Hard law) sean válidas para regular fenómenos complejos y, sobre todo de carácter supranacionales, tales como el cambio climático, la protección de los derechos humanos o el internet en las transacciones económicas y sociales, el comercio internacional, entre otros.

Esto ha significado una reestructuración del Derecho de orden supranacional, permitiendo la existencia de un nuevo ordenamiento jurídico donde se manifiesta el Derecho suave (Soft Law), enlazado con la creciente participación de actores sociales que demandan más espacios jurídicos para tratar temas relacionados con los distintos Derechos que se ventilan en este plano (internacional) y su impacto - vinculación - en el ámbito nacional de los Estados. A lo anterior también cabe añadir ciertas tendencias desreguladoras y privatizadoras, con lo cual el Estado ha dejado de controlar buena parte de la producción normativa en ciertos aspectos como el comercio. Con estos breves argumentos ponemos de manifiesto un primer acercamiento a esta dicotomía.

El Derecho Suave (Soft Law) y el Derecho Duro (Hard Law) son creados por actores diferentes, tal como lo refiere Gopalan, citado por Jaramillo Vernaza (2010), quien asegura la existencia de una competencia entre actores estatales y no estatales, afirmando que frecuentemente dicha pugna obtiene como resultado la prevalencia de los preceptos originados en los procesos legislativos del Derecho imperativo; aunque lo cierto es que hoy en día la tendencia se dirige a la aceptación tácita del Soft law por parte de las autoridades institucionales y, en menor medida, a su instrumentalización a través de procesos de inclusión. Sin embargo, esto en algunas ocasiones genera una solución a la incapacidad de lograr, por parte de los Estados, un desarrollo normativo acorde con la evolución del comercio, por lo que podríamos estar en presencia de una construcción legislativa de Derecho suave (Soft Law), comenzando con la preexistencia de un ordenamiento de carácter privado o informal surgido de agremiaciones de sujetos internacionales, dirigido a normativizar ciertas prácticas y de igual manera a condicionar la construcción de las regulaciones futuras.

De manera más específica podemos enunciar, como lo hicimos en párrafos preliminares, que estos actores no estatales pueden ser organizaciones internacionales, comunidades supranacionales o regionales, empresas multinacionales y organizaciones no gubernamentales, en lo particular señalamos al gremio de comerciantes que se han organizado en instituciones de carácter privado, indicamos lo anterior por lo preciso del corte de esta investigación.

Continuando con nuestro estudio, Oviedo Albán (2012) resalta la calidad autonómica de este tipo de Derecho (suave), y lo señala como una solución a las necesidades de distintos sujetos privados internacionales, entre ellos, los comerciantes, solución que nace precisamente del origen mismo de la norma y sobre todo de su flexibilidad que se traduce en una efectividad inmediata en el nivel transnacional, que depende del margen de utilización desarrollado en ese contexto. 
Expresado lo anterior, consideramos de vital importancia señalar que el Soft Law no está lejos de controversias jurídicas, dado que en cierta medida significa la perdida de la soberanía de los Estados, pero también una irremediable apertura a la internacionalización y democratización del Derecho internacional. La creciente adopción de instrumentos de Derecho suave (Soft law) de influencia internacional permite la participación de actores no estatales y adquieren más legitimidad que las leyes nacionales creadas para atender algunos asuntos. Sin embargo, en este orden de ideas se manifiesta el siguiente aspecto dicotómico: y es que el Derecho suave (Soft law) se aleja del Derecho duro (Hard law) debido a la falta de obligatoriedad directa que caracteriza a este último. Por lo general, el ámbito de Derecho suave (Soft law) se analiza en oposición al Derecho duro (Hard law) por su carácter obligatorio, cuyo incumplimiento puede ser exigido por las vías institucionales de solución de conflictos -órganos jurisdiccionales- (Del Toro Huerta, 2006).

Esta contraposición formal ubica al Derecho suave (Soft law) como instrumento en el que su obligatoriedad y efecto vinculante se diluye frente a las normas de Derecho imperativo creadas por los Estados. Empero, estos instrumentos en el espacio de la contratación internacional adquieren fortaleza mediante la denominada autonomía conflictual, los laudos arbitrales y en otras ocasiones por las resoluciones judiciales donde son reconocidos por los órganos de justicia nacionales, sobre este tópico volveremos en acápites posteriores.

A pesar de los aspectos dicotómicos de ambos ordenamientos, la finalidad del Derecho suave (Soft law) no es la de eludir los principios de seguridad jurídica, la imperatividad del Derecho duro (Hard law) o el imperio de la ley, sino que, pretende jugar, precisamente, en aquellos lugares de los que la clásica regulación basada en los fuentes tradicionales ya se ha retirado, es más, la existencia de actos o instrumentos de Soft Law solo puede admitirse si se produce desde la óptica de la coherencia del sistema jurídico sin atentar al principio de seguridad jurídica, además deben encontrar acomodo en el ordenamiento jurídico nacional, máxime en aquellas legislaciones donde la regulación de la autonomía de la voluntad es restrictiva. Este argumento es compartido por Pereznieto Castro (2012) quien expresa que:

De lo que se trata hoy en día es disminuir sino que desaparecer, las diferencias entre los diversos sistemas jurídicos, bajo la tesis moderna, que no atiende a sentimientos políticos o de defensa, sino simplemente a la constatación de la diferencia entre sistemas jurídicos internos y el internacional y de ahí, rescatar los vínculos entre esos dos derechos, que les permitan funcionar coordinadamente en beneficio del tráfico jurídico internacional, principalmente sobre el concepto de uniformidad (p.404).

González Martín (2011) se une a estas reflexiones, ya que para ella las normas de Derecho duro (Hard law) tienden a ser atenuadas por otros instrumentos 
internacionales de Derecho suave (Soft law), siendo que se perciben como directrices para los Estados y sus instituciones administrativas y judiciales. All (2013) utiliza el término de "codificación privada" para referenciar a un conjunto no sistemático de reglas de diversa índole que es a lo que venimos denominando Derecho suave (Soft law). No obstante, lo importante que enfatiza es que esta "codificación privada" se reparte espacios jurídicos con el Derecho duro (Hard law) y ambos, coordinada y armónicamente, cubren la totalidad de las relaciones y situaciones privadas multinacionales, afirmación con la que no concordamos completamente siendo que el desenvolvimiento de ambos ordenamientos en distintas ocasiones se contraponen y no permiten su pleno desarrollo, tal es el caso en que las normas imperativas de los Estados limitan la aplicación de normas de Derecho suave (Soft law) en los espacios nacionales, tal es el caso en que a los contratos privados se imponga determinados límites a partir del orden público como en Nicaragua donde la autonomía de la voluntad no puede ir en contra de la ley, la moral y el orden público según el art. 2437 del Código Civil (1904).

Es evidente que de la fuerza y la debilidad del Derecho suave (Soft law) podemos darnos la idea de puntos contrapuestos que se centran en la discusión dicotómica entre codificación pública versus codificación privada, como si fueran una y otra cara de la moneda. En realidad cabe preguntarnos si estamos frente a alternativas, complementos, o si hay un antagonismo cierto en el marco del proceso de gobernanza internacional. Es indudable que estamos ante un gran movimiento que produce transformaciones jurídicas y que viene dado con mayor fuerza por el lado del Derecho comercial, como consecuencia, entre otros factores, de la globalización.

Dicho esto y para concluir, hoy en día la realidad del Derecho suave (Soft law) encuentra puntos convergentes con el Derecho duro (Hard law), y es que en cuanto a las funciones que el Soft law cumple para con las normas imperativas estatales tenemos: a) Como avance, b) Como una alternativa, c) Como complemento, d) Como un parámetro interpretativo. Así la calificación del Soft law se ubica como fuente del Derecho en cuanto a un principio general, dado que este a su vez se nutre de fuentes generales del Derecho (Boretto, 2012), verbigracia las leyes modelo elaboradas en foros internacionales, algunos actos normativos característicos del Derecho institucional, convenios internacionales disponibles por las partes o la propia fuerza ejemplificativa de determinados convenios internacionales, actúan como fuentes a menudo en sentido impropio y pueden ser tenidas en cuenta por el legislador (Fernández Rozas, 2010), aunque esta postura en la doctrina es muy cuestionada bajo el amparo del numerus clausus del art. 38 del estatuto de la Corte Internacional de Justicia. Por lo tanto consideramos pertinente esbozar el contenido de este Derecho Suave (Soft Law) en el siguiente postulado. 


\section{Contenidos del Derecho Suave (Soft LaW)}

Primeramente, habrá que tomarse en cuenta algunos elementos comunes a los distintos instrumentos que se asocian con el concepto de Soft law. Tales instrumentos expresan expectativas comunes de conducta adoptadas generalmente en el marco de organizaciones internacionales y son creados o adoptados en su mayoría por sujetos de Derecho internacional (con la participación o no de otros actores internacionales), sin que para ello se siga todo el proceso tradicional para la creación de normas internacionales, y, en consecuencia, carecen de fuerza obligatoria (Del Toro Huerta, 2006).

Respecto a los criterios para determinar la existencia de un determinado instrumento del Derecho suave (Soft law) según Chinkin, citado por Del Toro Huerta (2006), identificamos los siguientes elementos: 1) Que sean formulados en términos no obligatorios de acuerdo a los procesos tradicionales de creación de derechos (v. gr. tratado o costumbre); 2) Que contengan términos vagos e imprecisos; 3) Que procedan de órganos internacionales; 4) Que estén dirigidos a actores no estatales; 5 ) Que se basen exclusivamente en la adhesión voluntaria y no exista un mecanismo jurídico para su exigencia. Sobre estos elementos discurrimos del segundo punto planteado por el referido autor, siendo que no siempre debe concurrir los términos vagos e imprecisos en los instrumentos de Derecho suave (Soft law), todo lo contrario, muchos de ellos poseen términos preciso en el ámbito comercial que describen con mayor certeza la regulación del acto o negocio jurídico.

Un acercamiento al contenido de este Derecho nos los propone Oviedo Albán (2012), quien afirma que todos aquellos instrumentos que derivan de otros centros de producción normativa, como son los contratos, o en algunos casos, los llamados códigos de conducta y los reglamentos de carácter profesional, que obedecen a la tendencia a dictar instrumentos de autorregulación, son consideramos como Derecho suave (Soft law). De forma más precisa Boretto (2012) formula las siguientes categorías: a) Resoluciones no obligatorias de los organismos internacionales, b) Resoluciones de actores no estatales, c) Acuerdos interestatales no normativos, d) Tratados concluidos que no han entrado en vigor, un ejemplo de este último enunciado es el caso de la Convención de Viena de 1980 sobre la Compraventa Internacional de Mercaderías en Nicaragua, la cual no ha sido ratificada, por lo que su aplicación deviene de la autonomía conflictual de las partes.

Los aportes brindados por los autores citados han sido relevantes para determinar el contenido del Derecho suave (Soft law). No obstante nos decantamos por la clasificación creada por Fernández Rozas, Arenas García, \& De Miguel Asensio (2013), la cual es más atingente a los objetivos de esta investigación: 1) Directriz habilitante, en esta primera manifestación, a manera de ejemplo, los Estados a través de una directiva comunitaria pueden adecuar su Derecho nacional, o bien, influir en las actuaciones y decisiones judiciales ${ }_{i} 2$ ) 
Leyes modelo, la cual debe entenderse como un texto legislativo que suele ser adoptado, por lo general, en el seno de una conferencia internacional, que se recomienda a los Estados para su incorporación al Derecho interno. No tiene un carácter obligatorio directo, incluso los Estados no tienen obligación alguna de comunicar al órgano codificador o a otros Estados que han incorporado el texto, sino que su función es inspirar al legislador interno a la hora de codificar una determinada materia cubierta por dicha ley modelo; 3 ) Códigos de conducta, constituyen instrumentos jurídicos que pretenden regular algunos aspectos de las relaciones privadas internacionales como, principalmente, las actividades de las empresas multinacionales en los países de acogida. Son concebidos como un conjunto de principios y de normas relativas al comportamiento de ciertos agentes internacionales que se incorporan a un solo acto jurídico adoptado por los Estados.

Es importante resaltar que en el marco de las transacciones privadas internacionales los códigos de conducta constituyen una suerte de acuerdo sistemático de normas, generalmente de carácter programático, que regulan la conducta de unos determinados sujetos del comercio internacional en unos ámbitos concretos de actuación, la nota definitoria de estos instrumentos no es otra que la flexibilidad, que se refleja en el cumplimiento voluntario de sus postulados y en la auto regulación que incluye, al margen de las normativas estatales, la inclusión del término "código". Muestra una orientación sistemática en el agrupamiento de las disposiciones que se recopilan, y una determinada voluntad de construir un cuerpo normativo coherente que lo distinga de una mera recopilación. Ello implica un cierto grado de unidad o integración en su contenido (Fernández Rozas et al., 2013).

Continuando con esta clasificación tenemos: 4) Guías legislativas, esto es un texto puramente indicativo elaborado por una institución internacional que evita los inconvenientes que ofrece la codificación a través de tratados internacionales. El empleo de esta técnica se ha generalizado en los últimos años en el seno de la UNCITRAL partiendo el avance de la tendencia a la autonomía legislativa que suele experimentar el legislador estatal a la hora de codificar determinadas cuestiones del derecho de los negocios internacionales (Fernández Rozas et al., 2013).

Habiéndonos acercado al concepto, naturaleza, contenido del Derecho suave (Soft law), y expresados los elementos dicotómicos con el Derecho duro (Hard law); nos resta expresar que lo fundamental de estas manifestaciones doctrinarias es evidenciar el elemento no vinculante de estos instrumentos que han adquirido vida en el contexto internacional mediante la actuación de actores no estatales, y que a su vez ha respondido a la necesidad de cubrir la falta de regulación por parte de las normas imperativas nacionales sobre ciertos temas, entre ellos el comercio internacional. A la par del análisis de esta realidad, existe otra que alimenta a los instrumentos de Derecho suave (Soft law), y que es de gran relevancia para el comercio y la contratación internacional, 
nos referimos a la Lex Mercatoria, por lo que abordaremos su tratamiento en el sucesivo acápite.

\section{LEX MERCATORIA Y DERECHO SUAVE (SOFT LAW). DOS REALIDADES INTEGRADAS}

Antes de iniciar la discusión propuesta en este apartado, es menester manifestar que el objetivo que perseguimos es configurar la diferencia que existe entre Lex Mercatoria y Derecho suave (Soft law), así como plasmar la intrínseca relación que ambos términos poseen en el marco del Derecho comercial internacional y la contratación internacional. Considerar a la Lex Mercatoria como un ordenamiento jurídico autónomo se ha debatido ampliamente entre positivistas, subjetivistas, mercatoristas y anti-mercatoristas, generando posturas irreconciliables. Por lo que se hace necesario diseñar el concepto y contenido de ésta, para determinar si estamos frente a un auténtico sistema jurídico para ser incorporado a las contrataciones internacionales por medio de la autonomía conflictual de las partes, espacio donde se entrelaza con aquellos instrumentos de Derecho suave (Soft law).

\section{La LeX MerCatoria. La aUtonomía de Un NUEVO ORDENAMIENTO JURÍDICO}

Hablar de Lex Mercatoria es evocar el desarrollo y evolución del Derecho en manos de los comerciantes desde el siglo XII, y al igual que el Derecho suave (Soft law) su conceptualización no es tarea sencilla. Clerc (2013) nos ilustra que la Lex Mercatoria, o bien, Ius Mercatorum, originariamente era un término designado para identificar a un conglomerado de normas jurídicas que regulaba la actividad comercial durante la primera Edad Media y, usualmente, fijadas por los mismos comerciantes y artesanos y sin que interviniera allí alguna autoridad, edicto o apelación a norma superior, lo cual, transformaba a esta Lex Mercatoria, en un derecho claramente consuetudinario. Es necesario destacar que, surge en clara oposición al Derecho de los señores feudales y a sus privilegios, y ante la insuficiencia normativa del Derecho civil para proveer una respuesta adecuada al notable crecimiento de la actividad comercial de ese entonces. Su aplicación cayó en desuso, claro está, hacia los inicios de las grandes codificaciones jurídicas que tuvieron lugar, la primera de ellas, durante la llamada Alta Edad Media y, luego, la segunda, hacia el final del siglo XVIII, perdió fortaleza, mas no desapareció.

Es así que, modernamente, las mismas causas que en sus orígenes la crearon, hoy nuevamente la hacen reavivarse. El fenómeno de la globalización y su influencia en el comercio internacional, la falta de producción normativa por parte del Estado específicamente en la materia comercial, el creciente tráfico del comercio, la proliferación de organismos internacionales, el desarrollo y 
la aplicación de la autonomía de la voluntad de los contratantes, son factores torales que han permitido el resurgimiento con mayor fortaleza de este ordenamiento jurídico que posee ciertos elementos comunes con el Derecho de los comerciantes en aquel período; sumado a esto el nuevo Derecho de comercio internacional, donde la Lex Mercatoria despliega sus efectos, ha surgido en la práctica de los comerciantes pertenecientes a distintos Estados con diferentes sistemas políticos, económicos y sociales, así como con distintos niveles de desarrollo (Espinoza Quintero, 2009).

En este orden de ideas, Tobar Torres (2012) participa en la construcción de este concepto (el cual tiene numerosos expositores). Así, denomina como una nueva Lex Mercatoria al conjunto de reglas de comportamientos y cláusulas de interpretación uniformes y típicas que se generan de manera constante y reiterada en el comercio internacional y que son asumidas por los particulares en virtud de la existencia de una convicción de carácter vinculante que es calificada como usos y costumbres del comercio internacional -o bien, que delimita su contenido-. Fernández Rozas (2000), es más preciso al conceder sin duda alguna a la Lex Mercatoria, la categoría de ordenamiento jurídico creado a manos de la "sociedad internacional de los comerciantes", en buena medida autónoma respecto de los Estados; y el hecho de que, pese a las diferencias entre los sistemas políticos y económicos, evidencia que existe un Derecho autónomo del comercio, nacido de las propias exigencias de éste, y que se ha desarrollado con independencia de estos sistemas jurídicos nacionales.

Además de esto, claramente se manifiesta que un sector relevante de las fuentes de la nueva Lex Mercatoria está integrado por lo que genéricamente se califica de usos y costumbres del comercio internacional. Esto lo reafirma Tobar Torres (2012), quien nos plasma el concepto dado por Goldman, uno de los primeros autores que utilizaron este término, para quien la nueva Lex Mercatoria se trata de: "reglas transnacionales que los participantes en los intercambios económicos internacionales se dan progresivamente a sí mismos, notablemente en el marco de sus organismos profesionales y que los árbitros constatarán y precisarán, teniendo en cuenta la intención de su elaboración" (p. 248), reglas que derivan de usos y costumbres entre estos participantes que han encontrado su fundamento en la utilización reiterada de las mismas.

Por otro lado, Berman y Dasser, citados por Giménez Corte (2002), consideran que la nueva Lex Mercatoria es Derecho de raíz consuetudinaria, como lo era la antigua, dado que está formada por usos que constituyen un Derecho espontáneo, uniforme, y en cierta manera universal ${ }_{i}$ que son usos propios de los comerciantes, y que tratan de superar las dificultades propias del conflicto de leyes cuando se trata de determinar el Derecho nacional que regirá una determinada relación jurídica. Sin duda alguna, son normas que carecen de la fuerza de la ley; sin embargo están vigentes. Dentro de esta misma discusión se encuadra la duda que si cconstituyen costumbre jurídica? efectivamente la respuesta debe ser positiva y contundente, más aun en el espacio del Derecho 
comercial $_{i}$ inclusive normas tanto de Derecho suave (Soft law) y Derecho duro (Hard law) se han creado a partir de los usos y costumbres internacionales.

Es entonces que podemos afirmar, con propiedad, que la Lex Mercatoria se configura como un Derecho espontáneo, un nuevo ordenamiento autónomo creado por los propios comerciantes, con el propósito fundamental de evitar en sus transacciones internacionales a la aplicación, siempre conflictiva, de las legislaciones locales de sus respectivos países, liberándose de la rigidez y de la falta de sensibilidad para el tráfico mercantil internacional de estas últimas. A partir de estas reflexiones podemos manifestar que son dos las notas que permiten caracterizar la Lex Mercatoria: su "anacionalidad", es decir, no emana de un sistema jurídico propio de un Estado soberano y, en segundo término, la fuerza obligatoria que le otorga la comunidad comercial internacional, aunque en ciertas ocasiones esta fuerza vinculante se contrasta con las Normas de Derecho sustantivo de los Estados.

Para Navarro Pentón (2009), además de los usos comerciales internacionales también los contratos-tipo y las condiciones generales elaboradas por las asociaciones mercantiles profesionales o por los organismos internacionales, constituyen las típicas fuentes de expresión de este Derecho de producción autónoma. Pereznieto Castro (1999) nos proporciona otra aproximación al contenido de Lex Mercatoria, compuesto por una amplia serie de reglas emitidas por organismos privados a nivel internacional o por órganos intergubernamentales a ese mismo nivel, pero cuya característica principal es que se trata de reglas que no tienen ningún origen y una obligatoriedad en su aplicación por parte de los Estados.

La referencia más precisa, consideramos que, viene dada por Giménez Corte (2002), primeramente determina a los usos, luego a los contratos internacionales; las condiciones generales de contratación y los standards forms; las reglas de las asociaciones profesionales y las guide lines; los principios generales del comercio internacional, y los restatements of law; los códigos de conducta, las convenciones internacionales aún no vigentes y ratificadas por los Estados, las leyes modelos; y los laudos arbitrales. Sobre este último punto queremos resaltar que la práctica y jurisprudencia arbitral ha permitido la instauración de este ordenamiento jurídico, de esto se encauza la vital importancia para la subsistencia y reconocimiento de la Lex Mercatoria.

Pasando a otro punto de análisis, a pesar de su demostrado carácter autónomo, la institución jurídica que venimos tratando no deja de ser objeto de crítica, por ejemplo, algunos doctrinarios enuncian que es un sistema que obedece a los intereses y necesidades específicas de un grupo social lo que le resta legitimidad dentro del Derecho internacional, puesto que sus promotores son un grupo social poderoso. Se señala igualmente que la Lex Mercatoria no es autónoma al condicionar su desarrollo a la aceptación que de ella tengan los Derechos estatales, sobre esto cabe reflexionar que su aceptación viene dada por la autorregulación que confiere la autonomía de la voluntad en su carácter 
conflictual. No obstante, lo único que puede atribuirse a esta afirmación es que en el plano contencioso nacional los jueces podrán limitar la aplicación de un Derecho derivado de la Lex Mercatoria consagrado en el contrato, cuando así lo considere el judicial. Es por esto que ha tomado mayor auge la práctica arbitral que plenamente reconoce este nuevo ordenamiento jurídico (Rodríguez Fernández, 2012). Esas críticas provienen, en buena medida, de quienes aún consideran la vieja concepción de que sólo el Estado está facultado para producir normas, afirmación que ya hemos criticado líneas arriba.

La Lex Mercatoria tiene una importancia normativa que no depende de un Derecho local y tiene una especial importancia para el comercio y la contratación internacional, ya que las partes no se someten a ninguna jurisdicción nacional ni a un Derecho sustantivo nacional. Por consiguiente, la Lex Mercatoria se erige como un orden jurídico propio, aunque sea incompleto, y en alguna medida esté subordinado a los órdenes jurídicos nacionales en su aplicación y eficacia al momento de exigir su cumplimiento; dependencia que no afecta a su autonomía.

En la esfera del comercio y la contratación internacional este ordenamiento jurídico puede ser traducido y sistematizado mediante instrumentos de naturalezas flexibles y carentes de efectos vinculantes, que ocupan como fuente para su creación a la Lex Mercatoria, y es aquí donde encontramos esa intrínseca vinculación entre Derecho suave (Soft Law) y la denominada Lex Mercatoria. Esta vinculación ha sido objeto de diversos estudios, siendo que en muchas ocasiones ambos términos se han ocupado indistintamente, considerándose como sinónimos uno del otro, lo que no es correcto. Es por esto que, en cumplimiento a nuestros objetivos planteados edificaremos un entramado doctrinario y analítico que nos permita descubrir la diferencia de ambas figura, pero a la vez sus elementos integradores que consienten su perfecta unión y adecuación en el comercio y la contratación internacional.

\section{De la Lex Mercatoria al Derecho Suave (Soft LaW) EN EL COMERCIO Y LA CONTRATACIÓN INTERNACIONAL}

En primer orden, a pesar que la Lex Mercatoria y el Derecho suave (Soft law) tengan características muy similares, ambos no son equivalentes. Desde su conceptualización encontramos las primeras diferencias. Así, la Lex Mercatoria es un ordenamiento jurídico autónomo creado por los comerciantes, el cual se fundamenta en tres pilares: las prácticas del día a día de la comunidad internacional del comercio (comerciante), los usos codificados o no en convenciones internacionales y los principios generales del Derecho; pero sobre todo se caracteriza por ser espontáneo, llevando en sus raíces la voluntad de las partes; además su creación data desde siglo XII, mucho antes de que se hablará de Derecho suave (Soft law). Este último se traduce en normativas emanadas por actores no estatales (como organizaciones internacionales, agrupaciones 
gremiales, etc.), de forma tal que su carácter no es vinculante, pero si revestido de efectos jurídicos. Estos instrumentos contienen diversas exposiciones temáticas en relación al tipo de Derecho aplicable (mercantil, medio ambiente, propiedad intelectual, derechos humanos, etc.), en cambio la Lex Mercatoria es utilizada únicamente por la "sociedad de comerciantes".

Un punto en común, es que ambos han encontrado su desarrollo en el ámbito internacional, por parte de la Lex Mercatoria específicamente en el comercio, dado que ambos procuran llenar los vacíos jurídicos de la norma nacional en este tipo de relaciones (internacionales); y es por esto que, tanto los creadores y usuarios de estos Derechos se alejan de la aplicación de normas locales con el ánimo de no nacionalizar sus negocios jurídicos, lo que ha permitido un fuerte desarrollo en la construcción de un nuevo Derecho para los comerciantes. Por lo que podemos afirmar que, hoy en día, jerárquicamente la Lex Mercatoria ocupa un grado superior al sistema normativo estatal cuando se trata de operaciones que ocupan al Derecho mercantil internacional. Circunstancia favorecida por el amplio espacio destinado al ejercicio de la autonomía de la voluntad, como elemento esencial para configurar las relaciones entre comerciante mediante la contratación internacional (Rapallini, 2011).

Bajo esta realidad entendemos, entonces, que la Lex Mercatoria se despliega por el denominado Derecho suave (Soft law), es decir, los instrumentos de este último, son resortes que propenden a la sistematización científica y fundada difusión de la Lex Mercatoria, acción que vincula de manera directa a los organismos internacionales que traducen los usos y costumbres (Lex Mercatoria) en instrumentos no vinculantes, un ejemplo de ellos son los denominados Incoterms. La relación intrínseca entre Lex Mercatoria y Derecho suave (Soft law) surge en el comercio internacional, dado que la normatividad mercantil como objeto de la ciencia jurídica, se ha ocupado desde sus inicios, en desarrollar una estructura que permita regular de forma independiente el carácter jurídico y socioeconómico de las relaciones entre particulares (Jaramillo Vernaza, 2010).

En consonancia con lo manifestado en el párrafo que antecede, en el Derecho mercantil contemporáneo las fuentes principales serán casi siempre, el desarrollo de las costumbres mediante las cuales se instrumentalizan las actividades mercantiles; la autonomía de la voluntad privada expresada en las formas contractuales más utilizadas en el ámbito comercial, y la asimilación por parte de organizaciones internacionales de comerciantes y de sus tribunales arbitrales, de reglas y principios aceptados por sus miembros.

Para continuar con el desarrollo de nuestro análisis nos cuestionamos ¿Cuál es importancia o el aporte que brinda tanto la Lex Mercatoria y el Derecho suave (Soft law) al comercio y la contratación internacional? Primeramente, Fernández Rozas et al. (2013) apelan al hecho de que el orden normativo no vinculante (Derecho suave) se nutre de normas específicas que resultan apropiadas para las relaciones internacionales que sean desarrolladas consuetudinariamente, en particular, en los principios generales del derecho de los negocios 
internacionales, usos y costumbres o la ya referida Lex Mercatoria. Por lo que se entiende como un conjunto normativo que no deriva de un ordenamiento estatal, concretamente sistematiza en muchas ocasiones usos y costumbres, creando una uniformidad en el comercio internacional ${ }_{\text {; }}$ pero que, además, propone la puesta en escena de las necesidades del comercio internacional y la aplicación de un ordenamiento neutral. Ello se evidencia en los procesos de producción y estandarización normativa, empero, al inicio de esta investigación dejamos sentando que los instrumentos de Derecho suave (Soft law) son utilizados por las normas imperativas nacionales, de tal suerte que sirve como recurso interpretativo lo que ayuda a su vinculación con los ordenamientos jurídicos, otorgándole cierto reconocimiento.

Sobre estos razonamientos no podemos desconocer la importante faceta normadora del Derecho suave (Soft law), que constituyen la dimensión contemporánea de la Lex Mercatoria, no obstante, esta última también ha sido acogida en los sistemas estatales a través de textos internacionales que institucionalizan su desarrollo, y sirve, además, para fijar sus contenidos y propiciar una mayor aplicación prospectiva por la propia sociedad de comerciantes, como ha ocurrido con la Convención de Viena de 1980 sobre compraventa internacional de mercancías, cuando ya está debidamente ratificada por los Estados (Fernández Rozas, 2000). Vale la pena aclarar que no siempre los instrumentos de Derecho suave (Soft law), se sustentan por la Lex Mercatoria, con todo, en materia de Derecho comercial internacional esta es fuente de este tipo instrumentos con mayor frecuencia.

Teniendo presente que la Lex Mercatoria es una realidad integradora de Derecho suave (Soft law), y ambas del comercio internacional, por lo que la importancia de este último deviene según Pereznieto Castro (2012) en su acomodamiento a diversas situaciones de carácter internacional, entre ellas el comercio, reduciendo la contradicción entre sistemas, en la medida que propenden a una uniformidad ${ }_{i}$ de tal modo que esta disciplina representa el motor del cambio y modernización del Derecho mercantil internacional, contemporáneo, pero que lo hace, a partir de categorías distintas a las que tradicionalmente se conocen en el Derecho interno. En este mismo sentido, afirma All (2013) que el Derecho suave (Soft law) es la puerta hacia una concepción más abierta, flexible, y plural del Derecho internacional, acorde con los tiempos de mayor globalización mundial, cuya dinámica se expande en un espacio transnacional y que a pesar de los paradigmas del positivismo estatalista, el progresivo ensanche del concepto de arbitralidad, en tanto las partes pueden utilizar normas elaboradas por organismos privados desprovistas de carácter vinculante, le confiere un carácter dominante en este ámbito.

Claramente, las fuentes del Derecho comercial que regulan las transacciones internacionales se han ampliado abarcando a la Lex Mercatoria y, como ya hemos visto, a una variedad de formas de Derecho suave (Soft law), como leyes modelo, guías legislativas, reglas y términos comerciales uniformes, por 
ende es preciso enunciar que la Lex Mercatoria en muchas ocasiones opera como Derecho suave (Soft law), dos realidades integradas, una comprensiva de la otra, o independientes, compartiendo o no determinadas características. Este escenario revela una acción manifestadora que procura la unificación de un Derecho del comercio internacional que demanda un aspecto dinámico y contribuye a dar a sus normas una contextura flexible, configurando un universo jurídico particularmente fluido, sin tener el ánimo de afectar el Derecho interno nacional y menos su soberanía (Sierralta Ríos, 2001).

Los procesos normativos en cuya virtud se elabora esta disciplina responden a la flexibilidad y dinamismo propios de este sector del ordenamiento internacional, y que pretende rodear de seguridad a las operaciones que se celebran y ejecutan en territorios y dotan de la mayor agilidad a los actos jurídicos, característica principal del comercio. Actualmente son seguidos por los Estados (a pesar de sus fuertes críticas por corrientes positivistas) y los operadores quienes los adoptan, de tal manera que la reiteración y referencias constantes dan paso a la configuración de una verdadera tendencia unificadora, por tanto en la medida en que se admiten y ponen en práctica van adquiriendo uniformidad y delimitación de su esfera de regulación, para Cortes Cabrera (2014): "No es sorprendente que se haya recurrido cada vez más a las soluciones de soft law ante las complejidades del actual orden mundial económico, ya que estas poseen una singular flexibilidad" (p.59).

La principal causa de la afirmación de Cortes Cabrera (2014) radica en la capacidad del Soft law de avanzar hacia esta unificación del Derecho sin soportar los costos de negociación que supone un proceso formal, asimismo responde, según los casos, a una búsqueda de fuga del Derecho que pretende proponer un nuevo realismo jurídico. Nos satisface declarar que el Derecho del comercio internacional es una realidad que en ciertas ocasiones ha encontrado respuestas por la vía del Derecho uniforme, por su inmediatez y por adecuarse a los intereses de las partes contratantes. Además, la creciente e inevitable interrelación económica de los países; la configuración de mercados comunes multinacionales; la proliferación de los tratados de libre comercio, para Díaz Bravo (2007) son, entre otras, las razones que explican y aun justifican la caudalosa corriente unificadora internacional del Derecho mercantil o comercial en todas sus expresiones, a tal punto que en el mundo moderno ya no es posible referirse a un Derecho mercantil puramente nacional o doméstico.

Para concluir este apartado, nuevamente ponemos de manifiesto que hemos demostrado la exclusiva relación que guarda la Lex Mercatoria y el Derecho suave (Soft law); ambas realidades de vital importancia para el comercio internacional, puesto que la transformación del Estado, por influjo de los procesos de integración económica, han modificado las formas de crear el Derecho, por tanto estos dos ordenamiento jurídicos permiten entrelazar nuevos mecanismo de producción normativa que atienden los diferentes contextos jurídicos, especialmente, los negocios comerciales internacionales. De manera 
concreta, exteriorizamos que el fenómeno de la globalización ha generado el desarrollo del Soft law y su íntima relación con la Lex Mercatoria, al igual que su recepción por los organismos internacionales, dada la importante acción que en este ámbito ejerce, y además su armonización reduce en gran medida las contradicciones existentes entre los distintos sistemas jurídicos nacionales (Fernández Rozas, 2010).

No queremos abandonar este apartado sin retomar lo que anteriormente expresamos, y es que parte de la doctrina cuestiona al Derecho suave (Soft law) como fuente, empero en esta materia habrá que considerar que la Lex Mercatoria se integra por usos y costumbres (reiterativos de los actores del comercio), por tanto siendo la costumbre como los principios fuentes aceptadas por el Derecho internacional, podemos afirmar que de manera mediata el Soft law parte de las propias fuentes reconocidas por el Derecho sin necesidad de recurrir a artilugios jurídicos inexplorados, tal como lo expresan González Rivera \& Castrillón y Luna (2015), pero esto solo puede afirmarse desde el ámbito del Derecho del comercio internacional.

Ahora bien, nos resta manifestar que la Lex Mercatoria alude a un ordenamiento jurídico que ha experimentado profundos cambios en la estructura de la sociedad internacional, en la práctica, podemos hablar de un Derecho autónomo nacido de las propias exigencias de la actividad y desarrollo de los comerciantes al margen de los sistemas jurídicos nacionales, su mayor manifestación son los usos y costumbres, los cuales en algunas ocasiones se han recogido en instrumentos elaborados por organismos internacionales, los que le han dotado un carácter normativo. Estos instrumentos son denominados Derecho suave (Soft Law), por carecer de elementos vinculantes, característica que comparte ambos conceptos, no obstante, no deben confundirse o darles el tratamiento de sinónimos, dado que por una parte la Lex Mercatoria, es un ordenamiento propio de los comerciantes en el plano internacional, mientras que los instrumentos de Derecho suave (Soft law), si bien es cierto, pueden configurarse a partir de la Lex Mercatoria, no siempre contienen este tipo de Derechos. Es entonces, que nos atrevemos a afirmar contundentemente que el Derecho suave (Soft law), es un vehículo que permite plasmar en normativas internacionales a la Lex Mercatoria, sin embargo no es la única vía por la que encuentra fundamento o asidero jurídico, también podemos referirnos a los contratos internacionales mediante la autonomía conflictual, y a los laudos arbitrales.

Por otra parte, para la contratación internacional (acción típica de los comerciantes que adquieren derechos y obligaciones en el ámbito del comercio internacional), tanto la Lex Mercatoria como el Derecho suave (Soft law) brindan una amplia gama de Derechos plasmados en instrumentos no vinculante que pueden ser aplicados por los contratantes. Ambos métodos son de producción normativa y cada vez más complementarios (Pereznieto Castro \& Silva Silva, 1995), por ende los operadores del comercio se alejaran cada vez más de los Derechos nacionales y solos recurrirán a ellos cuando tengan que hacer ejecutivo 
un derecho mediante los órganos coactivos del Estado. Esto se manifiesta a través de la consagración del principio de la autonomía de la voluntad, por el cual este tipo de instrumentos adquieren un carácter vinculante, razonamiento del que nos ocuparemos a continuación.

\section{El efecto vinculante del Derecho Suave (Soft LaW)}

Podrá sonar paradójico el título de este apartado, máxime que en el desarrollo de este artículo hemos sido enfáticos en decir que el Derecho suave (Soft law), al igual que la Lex Mercatoria, se caracteriza por carecer de efectos vinculantes; sin embargo pueden adquirir este carácter (vinculante) sin necesidad de ser incorporados en normas de Derecho duro (Hard law), lo que permite recrear su utilidad en el comercio internacional y más concretamente en la contratación internacional. Esto es posible mediante la autonomía de la voluntad manifestada en la contratación internacional, lo que constituye para Castrillón y Luna (2003) un uso imperativo que permite reglamentar los contratos celebrados entre comerciantes.

A este análisis se incluye Boretto (2012) quien indica que el componente auto normativo de los dispositivos de Derecho suave (Soft law), los torna obligatorios a través del consentimiento. Por lo tanto, este fenómeno adquiere efecto vinculante entre las partes y posee la virtud de equiparar a los actores estatales y no estatales en la creación de un marco regulador uniforme. Para sustentar más estas aseveraciones Ayoğlu (2014) expresa abiertamente que las partes son las que deciden incorporar las reglas a sus contratos ya sea de Derecho nacional o transnacional para regir sus negocios jurídicos.

Para Fernández de la Gándara \& Calvo Caravaca (1995) la mejor garantía de la efectiva adecuación del Derecho comercial internacional son los comerciantes mismos, quienes crean sin interferencia ajena su propio Derecho uniforme aprovechando en este sentido el espacio vacío de normas imperativas que viene determinado por el reconocimiento universal, en la esfera de la contratación internacional del dogma de la autonomía de la voluntad. En este punto coinciden la mayoría de los ordenamientos nacionales de los países de economía de mercado, al igual que aquellos de economía centralizada.

De igual forma concuerdan Sierralta Ríos (2001) y Pereznieto Castro (2012) que los instrumentos de Soft law devienen en obligatorios porque las partes libremente se obligan a adoptarlos entre sí, configurando un Derecho programático donde la prioridad de la autonomía de la voluntad de las partes y la incorporación en sus contratos de usos, costumbres e instrumentos de Derecho suave (Soft law), está por encima de su ley interna en la materia. Dicho de otra forma, en el momento en el que las partes incorporan a sus contratos Derechos anacionales, los convierten en normas obligatorias entre ellas y junto con su flexibilidad que ayuda a la armonización jurídica, pasa a ser como cualquier norma jurídica obligatoria, susceptible de ser demandada, 
incluso, ante tribunales nacionales, sin embargo algunos Estados aún son muy reticentes al reconocimiento de este tipo de Derechos en las contrataciones, aunque la apertura ha sido mayor.

Por tanto, en este ámbito, tal como expresa Bouza Vidal (2005), por regla general se considera que la autonomía de la voluntad prevalece sobre el Derecho positivo, de tal modo que las partes pueden excluirlo o modificarlo, además tal cual lo sostiene Mazuelos Bellido (2004) no se debe asumir per se el carácter no vinculante de los códigos de conducta (Soft law) auto normativos como Derecho suave, dado que en ocasiones devienen obligatorios para sus destinatarios a través del consentimiento expreso de éstos, lo que es una relevante expresión del fenómeno auto regulado de actores no estatales. A veces se recurre a la expresión "obligaciones voluntarias", que en realidad no deja de ser tautológica puesto que, en definitiva, las obligaciones son libremente asumidas por los sujetos, no vienen impuestas por terceros.

Tal como se puede inferir, las partes tiene la potestad de configurar sus relaciones contractuales internacionales, al amparo de la autonomía de la voluntad (García Castillo, s.f.), en sus dos vertientes: material y conflictual, la primera atiende a la facultad que tienen las partes de decidir con quién y cómo contratar (libertad de configuración), elegir comprometerse en una relación contractual con un tercero, así como la determinación del contenido del mis$\mathrm{mo}_{\text {; }}$ mientras que la segunda determina la legislación aplicable al problema, así lo manifiesta Dávalos Fernández (2003). Esto pone de manifiesto la voluntad soberana de las partes para conducir la celebración del contrato y para determinar sus efectos admisibles el reconocimiento, fruto de la autonomía de la voluntad. En este orden de ideas, Fernández Rozas (2004) lo expresa de la siguiente manera: "La ley aplicable a un contrato es la base legal que da la expresión y el contenido a la voluntad de las partes" (p.36).

Al igual que los autores anteriores, Leible (2011) opina que la autonomía conflictual, concede a las partes de un contrato la libertad de elección del Derecho, por ende, pueden decidir a qué Derecho se somete la relación jurídica existente entre ellas. Doctrinariamente se reconoce que de esta autonomía se origina "el principio de libertad de elección del Derecho aplicable". Ortiz Vidal (2012) agrega que esta libertad debe traducirse en la escogencia de un Derecho sustantivo nacional (Ley), o bien la Lex Mercatoria o un instrumento de Derecho suave (Soft law), planteamiento con el que estamos totalmente de acuerdo, y es que el argumento de más peso es sin lugar a dudas el respeto de los intereses de las partes y la ganancia en seguridad jurídica que ésta comporta.

La autonomía conflictual no es absoluta, a pesar que no es objetivo de nuestra investigación, manifestamos que existe un factor limitativo de la potestad de autorregulación basado en el orden público de los Estados (limitante que también manifiesta el Derecho nicaragüense en su norma civil), es decir, no está totalmente exenta de problemas, debido a que ellos pueden presentar limitantes en su aplicación por los Derechos estatales, y sus normas de orden 
público coartan la autonomía de la voluntad privada (Calderón Marenco, 2017). Verbigracia de esto lo expone Giménez Corte (2002) siendo que si es necesario recurrir a un juez nacional para solicitar el cumplimiento del contrato donde se haya establecido un Derecho no estatal para su regulación, este juez controlará que el Derecho aplicable al contrato no viole los principios de orden público del Estado donde pretenda hacerse valer, o sea contrario a su Derecho positivo.

Por otra parte, también tenemos que el efecto vinculante del Derecho suave (Soft law) se adquiere mediante su aplicación en los tribunales arbitrales (cuando las partes hayan decidido someter sus controversias a estos tribunales), quienes son usuarios y desarrolladores de este. La importancia del uso de Derecho suave (Soft law) en el contexto del arbitraje radica en su poder descriptivo, es decir que se proporciona un marco jurídico neutro compuesto de reglas del juego necesarias para un marco estable y transnacional para la realización de negocios. Los Incoterms son un ejemplo de este marco descriptivo y facilitador (Di Matteo, 2013), de igual forma exterioriza Pereznieto Castro (2013) que cuando existe una cláusula de Derecho aplicable en donde se determine a la Lex Mercatoria o al Derecho suave (Soft law) como tal, los árbitros deben construir su decisión de manera que corresponda a la legitima voluntad de las partes; concediendo efectos vinculantes a los Derechos escogidos por ellos (las partes), asimismo considera Carrasco González (2011) que la cláusula del Derecho o la ley aplicable debe ser una de las más importantes en los contratos internacionales.

El árbitro ha de ser fiel cumplidor del mandato de las partes sobre el Derecho aplicable, pues sus facultades están limitadas por el poder que ellas le han conferido, pues, debe acomodarse a dicha remisión y aplicar el bloque normativo seleccionado, de esta manera la Lex Mercatoria propia o bien manifestada por un instrumento de Derecho suave (Soft law) se ha convertido en un elemento fundamental, considerada por la jurisprudencia arbitral con el mismo rango que los sistemas jurídicos estatales, afirmando expresamente la juridicidad de sus normas precisándolas e, incluso, creándolas (Fernández Rozas,2004).

Como bien destaca Oviedo Albán (2012), estos instrumentos cuyo valor normativo no depende de la voluntad legislativa de los Estados, sino de la voluntad de las partes de incorporarlos a los contratos, depende también de la decisión de los árbitros y jueces de fallar conforme a ellos al reconocerlos como manifestación de la Lex Mercatoria o, en definitiva, por su propia fuerza persuasiva, tal como ha sucedido con los Principios de Unidroit para los contratos comerciales internacionales; las reglas y usos uniformes sobre crédito documentario ${ }_{i}$ los Incoterms, etc. Sin embargo, al igual que la autonomía conflictual, presenta sus limitantes siempre devenidas del ordenamiento nacional ${ }_{i} \mathrm{y}$ es que todo funciona satisfactoriamente hasta el momento de ejecutar la decisión de los árbitros en algún Estado mediante sus órganos jurisdiccionales, los cuales podrán negarse a reconocer legitimidad de la jurisdicción arbitral, al Derecho seleccionado o crea- 
do por las partes en razón de sus intereses y al laudo resultante. Así, la eficacia y ejecutabilidad del laudo arbitral puede caer en riesgo (Revoredo de Mur, 1994).

Sin embargo, hoy en día, existe una clara tendencia en el Derecho contemporáneo de los Estados a admitir la validez del pacto de elección de Derecho aplicable a contratos internacionales, así como la jurisdicción arbitral y el reconocimiento de sus laudos internacionales. En Nicaragua, la Ley de mediación y arbitraje (2005), en su artículo 54, permite que el tribunal arbitral decida el litigio de conformidad con las normas de Derecho elegidas por las partes como aplicables al fondo del asunto, y en sus decisiones tendrá en cuenta los usos y costumbres aplicables al caso; la estructura del articulado prioriza la escogencia de un Derecho sustantivo, lo que puede generar críticas sobre la permisión de un instrumento de Derecho suave (Soft law).

Para los autores nicaragüenses Orúe Cruz \& Meza Gutiérrez (2009), en todos los asuntos, además de las cláusulas contractuales, debe tomar el tribunal arbitral en cuenta los usos y costumbres que resultaren aplicables, en caso de ser necesario, auxiliándose igualmente de instrumentos tales como los Incoterms. En este mismo sentido, Robleto Arana (2010) expresa que el tribunal debe resolver en base al ordenamiento jurídico que las partes decidan, sobre esto debe comprenderse que este ordenamiento, a como bien afirma, puede ser la Lex Mercatoria, afirmación con la estamos completamente de acuerdo, a pesar de que la ley enuncia que debe entenderse como Derecho sustantivo de un Estado: "...Se entenderá que toda indicación del derecho u ordenamiento jurídico de un Estado determinado se refiere, a menos que se exprese lo contrario, al derecho sustantivo de ese Estado" (Ley de mediación y arbitraje, 2005, art. 54). Tal como manifestamos, consideramos que la legislación nicaragüense propende a una aplicación del Derecho estatal, y es que cuando no se establece un Derecho aplicable por las partes, el articulado permite al tribunal arbitral determinar la "ley aplicable", por lo que consideramos que la redacción correcta debería ser: "un Derecho aplicable", porque el tribunal no solo debe ceñirse a determinar a un "Ley" Estatal.

En consonancia con este instrumento legal, el Código de procedimiento civil (2015), en su artículo 27, determina que en caso de existir un acuerdo arbitral para someter la controversia, los jueces civiles deberán abstenerse de conocer. De igual manera el art. 410 limita la ejecución del laudo arbitral, hasta que por medio del análisis la autoridad judicial competente verifique el respeto a las normas de orden público y la legalidad de su contenido, y si se cumple con ello despachará ejecución. No obstante, su denegación se hará mediante auto, contra el que cabe recurso de apelación. Sobre esto podemos apuntar que existe la posibilidad que el Judicial restrinja la autonomía de la voluntad dado que del examen que realice del asunto en cuestión pueda establecer en su fallo que las decisiones adoptadas por las partes contravienen el orden público nicaragüense primando la voluntad Estatal y protegiendo su estructura legislativa, también debe tomarse en cuenta que Nicaragua es parte de la 
Convención sobre el Reconocimiento y la Ejecución de las Sentencias Arbitrales Extranjeras, conocida como la Convención de Nueva York de 1958, que establece que las decisiones arbitrales pueden ser exigidas y perseguidas en tribunales nacionales.

Sin embargo, en otras sedes estatales, las decisiones judiciales confieren efectos vinculantes a los instrumentos, es así que Giménez Corte (2002) y Jaramillo Vernaza (2010) consideran que el Juez debe determinar el Derecho aplicable a la garantía internacional, recurriendo a la costumbre jurídica transnacional, o a la Lex Mercatoria, y aplicarla aun sin elección expresa por las partes. Lo que permite ser fuente de pronunciamientos judiciales posteriores, denotando una inclusión directa de estos instrumentos y otorgándole un carácter vinculante. Por ejemplo, en Colombia, la Corte Suprema de Justicia en fallo de 21 de febrero de 2012 se pronunció favorablemente en pro de la posibilidad de escoger como ley del contrato un instrumento de Derecho suave (Soft law) como son los Principios de Unidroit sobre los Contratos Comerciales Internacionales (Oviedo Albán, 2012), particularmente aun en Nicaragua no existe sentencia alguna por parte de la Corte Suprema de Justicia en donde se pronuncie sobre este aspecto, sin embargo la legislación mercantil y arbitral, en teoría, está encaminada a favorecer la aplicación de usos y costumbres, aunque no sin antes de haberse realizado un control de legalidad por parte del órgano judicial a como bien lo hemos analizado, más aun cuando nuestras leyes no utilizan los términos correctos.

Hemos construido firmemente la diferencia entre Lex Mercatoria y Derecho suave (Soft law), al igual que su intrínseca relación, demostrando la integración de dos realidades fundamentales para el comercio y la contratación internacional, así como el fundamento doctrinario, aunque paradójico, del carácter vinculante de este tipo de instrumentos y sus limitantes derivadas de los ordenamientos nacionales. Hasta este punto nuestra investigación ha cumplido abundantemente con sus objetivos, entramando nuestra posición frente a este amplio espacio de análisis que genera el Derecho suave (Soft law) y, a la par de él, la Lex Mercatoria. Dentro del espectro de instrumentos de Derecho suave existen, un sin número de ellos, no obstante para nuestra investigación y lograr demostrar la exclusiva relación que edificamos entre Lex Mercatoria y Derecho suave (Soft law) hemos escogido a los Incoterms como instrumentos nacidos de ambas vertientes, con los que expondremos de manera más puntual su indudable utilidad como instrumentos de Soft law tanto para el comercio como para la contratación internacional, y la recepción en los Derechos nacionales.

\section{LOS INCOTERMS COMO INSTRUMENTO DERECHO SUAVE (SOFT LAW)}

Antes de iniciar el abordaje de estos términos, considerados como una manifestación de la Lex Mercatoria traducida en un instrumento de Derecho Suave 
(Soft Law), queremos plasmar lo expresado por Herrera Espinoza \& Guzmán García (2014), quienes apunta que la propia práctica del comercio internacional ha favorecido a la Lex Mercatoria; convirtiendo a los usos y practicas uniformes elaborados por los propios operadores económicos en una serie de cláusulas contractuales y términos que facilitan la negociación, es así que la Cámara de Comercio Internacional (CCI) ha desarrollado una importante labor de creación, recopilación y difusión de estos usos y reglas uniformes, cuya manifestación más relevante son los llamados Incoterms.

\section{EVOLUCIÓN, CONCEPTUALIZACIÓN Y NATURALEZA JURÍDICA DE LOS INCOTERMS}

Desde inicio del pasado siglo, el comercio internacional experimentó gran auge, sin embargo al empresario comerciante, que a título individual o agrupado en sociedades mercantiles comerciaba con otras naciones, se le presentaban graves problemas, relacionados con el desconocimiento de las leyes de otros Estados; el de sus usos y costumbres; el idioma, entre otros. Por ello, fue objetivo de la Cámara de Comercio Internacionales (CCI), el crear unas normas sintéticas que permitiesen, con el mínimo esfuerzo, conocer los derechos y obligaciones de las partes, sobre todo las más esenciales (Chuliá Vicent \& Beltrán Alandete, 1995); por su parte Fratalocchi (1994) apunta a que el origen de estos términos, además de vincularse con el desarrollo del comercio mundial, se sustenta en la necesidad de sistematizar ciertos usos y costumbres en la compraventa internacional de mercaderías.

Es así que, en el primer congreso de la Cámara de Comercio Internacional (CCI), realizado en París en 1920, se iniciaron los trabajos que resultaron en el estudio del derecho, usos y prácticas de más de 30 países, conclusiones que se editaron en 1928, pero fueron publicados por primera vez en 1936, por la ya citada cámara. Éstas obtienen gran éxito. No obstante, el uso y la experiencia aconsejaron reformas en 1953, 1967, 1976, 1980, 1990 y 2010 (última versión, actualmente vigente).

Los Incoterms se crearon para ser aplicados en las contrataciones de compraventa internacional de mercaderías. Éstos regulan las obligaciones, costes y riesgos que implica la entrega de las mercancías de los vendedores a los compradores, de manera más concreta disponen el lugar y condiciones de entrega de las mercancías, la transmisión de los riesgos del vendedor al comprador en el momento de la entrega, y el reparto de costes, como los de seguro, flete o las licencias de importación y entrega de documentos. A medida que se incrementaba el uso de estos términos, la lista inicial de precisiones y sistematizaciones de los términos comerciales internacionales (la que incluía 11 términos) ha ido produciendo una serie de actualizaciones; en algunos casos eliminando e incluyendo nuevos términos, o bien, modificándolos (Huamán Sialer, 2013). Es necesario precisar que la evolución de dichos términos también obedece 
a las nuevas tendencias del comercio, así como la creación de nuevos usos y costumbres a nivel internacional.

La versión actual recoge 11 términos, y en esta ocasión la Cámara de Comercio Internacional (2010) tomó en consideración la gran influencia que la economía global ha ejercido sobre las empresas, lo que ha permitido la apertura a nuevos mercados, aumentando el tráfico comercial internacional y nacional. Es por esto que se ha autorizado que estos usos puedan utilizarse en contratos de compraventa nacional. Otro aspecto relevante de esta última versión versa sobre la comunicación electrónica, siendo que las reglas Incoterms 2010 otorgan ahora a los medios de comunicación electrónicos el mismo efecto que la comunicación en papel, en la medida en que las partes así lo acuerdan o cuando se lleva a cabo con fundamento en la costumbre. Esta fórmula facilita la evolución de nuevos procedimientos electrónicos durante la vigencia de estas reglas.

Los términos que contiene la versión actual son: EXW (Entrega en Fábrica en lugar convenido), FCA (Franco transportista lugar convenido), FAS (Franco al costado del buque puerto de carga convenido), FOB (Franco a bordo en puerto de carga convenido), CFR (Coste y flete hasta puerto de destino convenido) CPT (Transporte pagado hasta puerto de destino convenido), CIF (Coste, seguro y flete), CIP (Transporte y seguro pagados hasta, puerto de destino convenido), DAT (Entregado en terminal de puerto de destino convenido), DAP (Entregado en un punto, lugar de destino convenido) y DDP (Entregado derechos pagados hasta lugar de destino convenido); estos se encuentran agrupados en cuatro grupos.

El grupo E implica el mínimo de obligaciones para el vendedor, pues éste cumplirá su obligación de entrega poniendo a disposición del comprador la mercancía en su propio almacén o fábrica, el grupo $\mathrm{F}$ tiene como característica común el hecho de que dejan a cargo del comprador los gastos principales del transporte de la mercadería ${ }_{i}$ mientras el vendedor se obliga a entregar la mercancía al transportista, designado por el adquirente, en un lugar y tiempo determinado y hasta ese momento asume los gastos de transporte y los riesgos derivados de la posible pérdida o daño de los bienes negociados; el grupo $\mathrm{C}$ se caracteriza porque la entrega se produce, como norma general, en el medio de transporte designado por el vendedor, quien corre con los gastos de transporte, pero no asume los riesgos de pérdida o daño de la mercancía desde el momento en que se produce la entrega, por último, en el grupo $\mathrm{D}$ el exportador asume todos los gastos y riesgos necesarios para llevar las mercancías a un lugar específico dentro del país de destino y el importador tiene menos obligaciones y recibe los bienes en su propia bodega (Calderón Marenco, 2017).

Para Marzorati (1993) los Incoterms son un conjunto de reglas aplicables internacionalmente y destinadas a facilitar la interpretación de los términos comerciales comúnmente utilizables, en el fondo son usos y costumbres codificados de aplicación no obligatoria. Huamán Sialer (2013) adiciona que son una redacción sumaria de las costumbres internacionales que constituyen un 
Derecho, elegido por las partes. De su conceptualización podemos deducir su naturaleza jurídica la cual es meramente dispositiva, y es que si bien es muy importante reconocer el funcionamiento de los Incoterms, no debemos olvidar que no son normas obligatorias para las partes, a menos que así lo acuerden expresamente, incluyendo su sigla en el contrato de compraventa internacional de mercaderías, por tanto su origen o naturaleza viene dada por la voluntad las partes, en tanto que estos términos son dispositivos, pueden incluirse o no en los contratos según lo que ellas acuerden.

Es por esto que Jerez Riesco (2007) asevera que estos términos tienen carácter facultativo, por lo que se pueden celebrar contratos de compraventa internacional sin tomarlos en cuenta ni consideración. Asimismo, Boyeras Schumman (2012) sostiene que: "la naturaleza de los Incoterms es contractual y no normativa. A pesar de ello, esa ausencia de carácter normativo no supone una merma en la importancia de los Incoterms en la práctica internacional" (p.126). Sobre la base de estas reflexiones doctrinarias, indudablemente, nos parece que la naturaleza de estos términos es la de tratarse de normas de carácter dispositivo, otorgándole a la parte la facultad de poder disponer o no de ellos en sus contrataciones, esto también deviene por ser característico de los usos y costumbres, o bien, de la Lex Mercatoria.

\section{LOS INCOTERMS COMO MANIFESTACIÓN DE LEX MERCATORIA E INSTRUMENTO DE DeRECHO SUAVE (SOFT LAW)}

Razona Fernández Rozas (2004) que la condición de los Incoterms, meramente facultativa, configura la cristalización de una serie de prácticas comerciales internacionales, que se han normalizado y sistematizado con el ánimo de armonizar las operaciones internacionales de comercio internacional. Su gran difusión, con la que cuentan hoy, les ha dotado de un valor considerable como auténticas normas reguladoras de las relaciones contractuales entre las partes. Atendiendo al hecho de que éstos son una redacción sumaria de la costumbre, los Incoterms son un reflejo de la denominada Lex Mercatoria (Ortega Giménez, 2008). En la edificación de la afirmación anterior participan Fernández de la Gándara \& Calvo Caravaca (1995), para ellos la Lex Mercatoria se traduce en la acción normativa de los comerciantes mediante corporaciones profesionales y que además son independientes del Derecho estatal, tal como sucede con los Incoterms.

Bajo el concepto de Lex Mercatoria, que plasmamos líneas arriba, los Incoterms pueden ser acogidos dentro del mismo, dado que se ha reconocido que son usos y costumbres que se han compilado desde 1936 por la Cámara de Comercio Internacional, procurando facilitar una serie de términos de forma universal, en los contratos de compraventa internacional de mercaderías, especificando los derechos y obligaciones de las partes bajo cada uno de ellos. Es posible dejar asentado y con precisión que los usos y costumbres profesionales o locales 
que las partes han establecido en sus tratos los convierte en un Derecho que se superpone a las leyes nacionales, lo que permite dar vida a los Incoterms como manifestación de una Lex Mercatoria debidamente sistematizada (Acosta, 2002).

Tanto Bernitz (2013) como Chavarría Chávez (2013) aseguran firmemente que los Incoterms, gozan del estatus de práctica comercial, convirtiéndolos directamente en una manifestación de la Lex Mercatoria, por tanto en ellos se manifiestan los elementos integradores de este ordenamiento jurídico. Son entonces, los Incoterms un componente de la Lex Mercatoria, proveniente de una asociación gremial con autoridad para indicar que ciertas reglas y usos que de manera constante se están utilizando en el comercio internacional pueden instrumentalizarse.

Ahora bien, los Incoterms, además de ser una manifestación de la Lex Mercatoria, su sistematización por parte de la CCI les concede la categoría de instrumentos de Derecho suave (Soft law), y es que atendiendo a sus características no poseen verdadera fuerza normativa, en tanto no han surgido de un tratado entre Estados. Estas cláusulas tampoco quedan incorporadas a los Derechos nacionales mediante ningún acto normativo. Por tanto no pueden ser considerados como normas legales, dado que estos términos fueron elaborados por un organismo privado, fieles a las características de instrumentos de Soft law. Por ende son carentes de valor vinculante al no estar dotadas de fuerza coercitiva y, además, no se imponen a los contratantes si no es por medio de los acuerdos de voluntades (Oviedo Albán, 2003).

Como es evidente, no tienen fuerza de ley, se aplican única y exclusivamente cuando las partes han hecho referencia expresa a estos términos, lo que les confiere, sin duda alguna, el rasgo distintivo de su efecto jurídico, mas no vinculante, lo que encaja dentro de los códigos de conducta, como parte de la clasificación de los instrumentos considerados como Derecho suave (Soft law), que no entran en conflicto con normas imperativas o de orden público (Rodríguez Fernández, 2010), aunque, como ya hemos visto, en ciertas ocasiones pueden encontrar ciertas limitantes. Como demostramos en los acápites anteriores, los instrumentos de Derecho suave (Soft law), aunque suene incongruente, si se revisten de fuerza vinculante mediante la configuración de la autonomía de la voluntad, ello no es diferente con los Incoterms, es así que procederemos a evidenciar la manera de cómo estos adquieren este carácter.

\section{EFECTO VINCULANTE DE LOS INCOTERMS COMO INSTRUMENTO de Derecho Suave (Soft LaW)}

Definitivamente, lo obvio es que el efecto vinculante viene dado por la autonomía conflictual de las partes, sin embargo, a como mencionamos, estos términos solo pueden utilizarse en los negocios jurídicos de compraventa internacional de mercaderías, por ende ellos tiene una especial vinculación con la Convención de Viena de 1980 sobre compraventa internacional de 
mercaderías, instrumento reconocido por la doctrina como uno de los mayores éxitos de la creación de un Derecho uniforme internacional que brinda seguridad jurídica a los comerciantes, con el ánimo de facilitar los intercambios de bienes, capitales y servicios en un momento que tiende a la globalización económica, denotando así la creación de un Derecho supra nacional (Calderón Marenco, 2017).

Sobre esto debemos apuntar que los Estados partes de esta convención, reconocen la plena aplicación de los usos y costumbres en este tipo de negocio jurídico, lo que se manifiesta en un instrumento de Derecho duro (Hard law). En este sentido, expresa Ruiz Castellanos (2012) que la validez jurídica de estos términos proviene directamente de la Convención, a través de lo dispuesto en el art. 9. Por este motivo serían directamente aplicables al margen de lo dispuesto por los contratantes, afirmación que no compartimos del todo, debido a que ese hecho no los convierte en un instrumento vinculante, pero si les confiere a las partes mayor certeza y seguridad por la validez que le otorga esta convención como instrumento imperativo de los Estados.

La posición de Alzate Ossa (2013) radica en que la Convención de Viena de 1980 hace prevalecer los usos y prácticas mercantiles que las partes hayan convenido o establecido entre ellas, dentro de las cuales están preponderantemente los Incoterms; esto aunque las partes expresamente así no lo estipulen en el clausulado contractual, sin olvidar, claro está, el carácter marcadamente dispositivo de tales términos. La elección voluntaria para incorporar los términos encuentra su sustento en el art. 6 de la citada convención, siendo que establece la posibilidad de que las partes desplacen total o parcialmente las normas de la Convención en favor de normas o regulaciones ajenas al mismo, que en este caso podrían ser los Incoterms. Razonamos que tanto el artículo 6 como el artículo 9 son complementarios, siendo fieles al fin primordial del comercio como es la celeridad y adaptabilidad del mismo a las nuevas prácticas comerciales, por ende la convención va más allá de un simple texto normativo, lo cual permite la integración de la Lex Mercatoria (Calderón Marenco, 2017, p.34).

Así mismo, lo confirmó la Courd'appel de Versailles, Francia, en el Caso CLOUT $n .^{\circ} 225$ del 29 de enero de 1998, quien se ha ocupado de la relación entre el párrafo 2 del artículo 9 y los Incoterms, afirmando que están incorporados en la convención en virtud del párrafo 2 del artículo 9. Con arreglo a este artículo las definiciones de los Incoterms deben aplicarse al contrato aunque no haya una referencia expresa a ellos en éste. Así, el tribunal sostuvo que, al incorporar un término CIF a su contrato, las partes tenían la intención de aludir a la definición de ese término (Comisión de las Naciones Unidas para el Derecho Mercantil Internacional, 2010).

En razón de esto, los Incoterms cobran vida mediante la autonomía conflictual. Su acogimiento y cumplimiento deviene en voluntario y facultativo, lo que los convierte obligatorio para las partes que los han invocado en sus contratos. Oviedo Albán (2011) al respecto indica que las partes en uso de la libertad de 
pacto (autonomía conflictual), al escoger la ley del contrato podrían designar como tal un instrumento jurídico de Soft law, tales como los Incoterms. No obstante, el carácter vinculante también se adquiere mediante el reconocimiento que les otorgan los tribunales arbitrales.

Un ejemplo de esto es el laudo de la $\mathrm{CCI} n .^{\circ} 8502$, en donde las partes del contrato no acordaron expresamente la ley aplicable al mismo, hecho que no significó para el tribunal que el pacto de ley aplicable no pudiera deducirse de las relaciones entre las partes. No obstante, ellas habían hecho referencia a usos del comercio internacional, como los términos Incoterms 1990. Asumió el tribunal que la ley que debía regir el contrato eran las prácticas admitidas bajo el derecho del comercio internacional, sobre los cuales resolvieron el fondo del asunto, por consiguiente notamos que el reconocimiento y carácter vinculante vienen dado por estos tribunales.

Para finalizar las reflexiones de este acápite, debe tomarse en consideración que de los resultados de las prácticas comerciales internacionales y de la actividad institucional en el ámbito internacional pueden ser, asimismo, objeto de recepción individual por los distintos sistemas estatales, a través de la codificación interna. Ya bien lo dice Fernández Rozas (2000), nada impide que el legislador estatal utilice la técnica de la incorporación material, hacer suyas las leyes modelo o textos internacionales sobre arbitraje o usos y prácticas mercantiles; si bien es cierto le otorgaría de forma directa el efecto vinculante al convertirlos en instrumentos de Derecho duro (Hard law), sin embargo perdería la flexibilidad que hasta el día de hoy les ha ganado reconocimiento. Por tanto, debe hacerse una valoración precisa al momento de positivar usos, costumbres o instrumentos de Derecho suave (Soft law).

Como corolario de esta investigación es preciso apuntar que definitivamente hemos dejado establecido la diferencia que guarda el Derecho suave (Soft law) y la Lex Mercatoria, así como su intrínseca relación a partir del comercio internacional y de la proliferación de actores estatales que demanda su propia regulación con el ánimo de alegarse de las legislaciones estatales, es por esto que han creado instrumentos Derecho suave (Soft law), carentes de efecto jurídicos, que se nutre de la Lex Mercatoria (usos y costumbres comerciales internacionales), es decir que una vía para normar a la tan sonada Lex Mercatoria son los instrumentos de este Derecho; por lo que podemos vislumbrar que estas dos realidades autónomas se complementan y encuentran cabida a partir de su vinculación en las contrataciones internacionales mediante la autonomía conflictual.

El mejor ejemplo que hemos podido traer a colación para su análisis son los Incoterms quienes son una manifestación de la Lex Mercatoria y se han plasmado en instrumentos de Derecho suave (Soft law), resaltando su carácter facultativo, y es que mediante la incorporación a los contratos internacionales como Derecho aplicable, les confiere carácter vinculante. Asimismo hemos repasado en líneas anteriores que estas realidades y sus manifestaciones no están exentas 
de problemas a partir de contraponerlos con los sistemas imperativos estatales, sin embargo estructuramos las posibles soluciones que puede tomarse para complementar la validez de los mismos.

\section{APORTES Y RESULTADOS}

La regulación del comercio tanto a nivel nacional como internacional, ha dependido desde sus inicios de sus operadores, los comerciantes, y es que el comercio se ha valido de los usos y costumbres que se han creado en el seno de esta sociedad, con el ánimo de alejarse de las aplicaciones de normas estatales que no son congruentes con las prácticas comerciales, por su rigidez, y más aún en el plano internacional. En un comienzo, estos usos y costumbres se le denominaron Lex Mercatoria, la cual se erigió para consagrar las buenas practicas que regían la actividad comercial; sin embargo, con el transcurrir del tiempo los usos y costumbres fueron sometidos al proceso de codificación, es entonces que la sociedad de comerciantes debía regirse por las normas emitidas por los órganos estatales, que en cierta medida brindaban seguridad jurídica.

Con el tiempo, la práctica del comercio ha trascendido fronteras, las interrelaciones entre sujetos de distintos Estados es más común, máxime con el intercambio de bienes y servicios que permite la apertura a diferentes mercados y economías, esto también atiende a la fuerte influencia del fenómeno de la globalización, que ha reclamado un espacio en distintos ámbitos del ser humano y el Estado, entre ellos el comercio y el Derecho. Sobre este orden de ideas, el comercio se ha caracterizado por su agilidad y flexibilidad que no siempre son acordes a las normas imperativas, las que crean camisas de fuerza en las relaciones internacionales, más específicamente en las contrataciones de compraventa internacional de mercaderías.

En el ámbito internacional, los comerciantes han optado por regirse por sus propias costumbres, aplicando Derechos creados por sus propias manos. Esto ha permitido el resurgimiento de la Lex Mercatoria considerándose como un ordenamiento jurídico independiente. Es así que hemos demostrado de manera contundente la existencia de este Derecho espontáneo, autónomo, y uniforme que tiende de manera natural a alejarse de las regulaciones estatales, intentando de esta manera dar solución definitiva a los nuevos conflictos del comercio, por eso la Lex Mercatoria constituye un factor trascendental en el marco de las transacciones comerciales internacionales, a pesar de las críticas que le realizan los positivistas, quienes defienden la potestad soberana del Estado de crear normas.

La Lex Mercatoria es una fuente de Derecho propia del comercio, es un ordenamiento que engloba una serie de usos y costumbres; sin embargo también le confiere en muchas ocasiones validez a instrumentos creados por organismos internacionales que la expresan o plasman en sus contenidos. La sociedad de comerciantes ha otorgado la facultad a sus integrantes de dictarse sus propias 
reglas, desconociendo cualquier tipo de soberanía estatal, al mejor estilo del Derecho clásico mercantil. Las características de estas normas están estrechamente vinculadas con el término Derecho Suave (Soft law), acuñado por Lord McNair, el cual es utilizado para denominar a todos aquellos instrumentos creados por asociaciones profesionales o por los organismos internacionales, cuya característica principal es no poseer efectos vinculante pero si efectos jurídicos. Ahora bien, habrá que acotar que estos instrumentos pueden manifestarse en cualquier contenido o materia del Derecho (derechos humanos, propiedad intelectual, comercial, etc.)

Estos instrumentos han sido contrastados con las normas imperativas de Derecho Duro (Hard law), dado que su principal debilidad se manifiesta en su flexibilidad ante las normas imperativas, lo que es cuestionable desde el aspecto de la seguridad jurídica, máxime que son normas que provienen de actores no estatales, por ende se contraponen con la tradicional forma de hacer normas. Sin embargo la debilidad que se muestra frente a este Derecho imperativo le resulta ventajoso al Derecho comercial internacional, una realidad que en ciertas ocasiones ha encontrado respuestas por la vía del Derecho uniforme, los instrumentos de Derecho suave (Soft law) procuran una uniformidad en este ámbito. Esto se debe a que, en el dinámico contexto del mercado internacional, opciones como la del Derecho suave (Soft law) resultan especialmente apropiadas por la eficiencia de sus respuestas y soluciones, por su inmediatez y por adecuarse a los intereses de las partes contratantes, a como bien lo hemos puntualizado en el cuerpo de este trabajo.

La Lex Mercatoria y el Derecho suave (Soft law) guardan una intrínseca relación, y es que en el comercio internacional la primera se manifiesta mediante instrumentos de este tipo Derecho, especialmente porque ambos carecen de efectos vinculantes. En otras palabras, los usos y costumbres en ciertas ocasiones se traducen mediante el Soft law. Ambos encuentran limitantes en el orden público y las normas imperativas Estatales, pero localizan su fuerza vinculante mediante la autonomía conflictual de las partes contratantes, imponiéndose la libertad de ellos al momento de elegir el Derecho aplicable a sus contrataciones. Cabe entender que este Derecho no pude ser únicamente una ley Estatal, de modo que aquí es donde tiene cabida la noción de un ordenamiento jurídico constituido y compuesto por la Lex Mercatoria y los instrumentos Derecho suave (Soft law). No obstante, no solo mediante la autonomía conflictual puede adquirir efectos vinculantes sino también por las disposiciones de los tribunales arbitrales quienes en sus laudos reconocen la existencia de estos Derechos y el pleno respeto a la voluntad de las partes, en otras veces, también lo encontramos en las resoluciones judiciales, donde los jueces aplican normas de Derecho suave (Soft law).

Para finalizar con este análisis, en esta investigación hemos puesto de manifiesto que un ejemplo palpable de estas dos realidades integradas son los Incoterms, usos y costumbres que fueron compilados por la CCI en 1936. 
Términos que a todas luces son una clara manifestación de la Lex Mercatoria, y se han materializado mediante un instrumento de Derecho suave (Soft law). Ellos han sufrido el inevitable efecto de la evolución y la globalización, es por esto que han sido reformados dando pauta a la inclusión de costumbres y usos que se han actualizado, algunos de ellos por el constante avance de la tecnología. Además, se han revelado como un producto de la unificación del Derecho comercial internacional en materia de compraventa internacional de mercaderías, y que los Estados se han visto obligados a conceder un amplio margen de aceptación mediante la inclusión en las cláusulas contractuales.

\section{REFERENCIAS BIBLIOGRÁFICAS}

Acosta, F. (2002). Incoterms, Términos de Compraventa Internacional. México: Ediciones Fiscales ISEF.

AlL, P. M. (2013). Algunos interrogantes sobre la fuerza y la debilidad de la codificación privada internacional. En D. Fernández Arroyo, Derecho Internacional Privado y Derecho de la Integración (págs. 169-204). Asunción: CEDEP.

Alzate Ossa, M. (2013). Los Incoterms, el contrato de seguro y la compraventa internacional de mercaderías: la transferencia del dominio y del riesgo en el contrato de compraventa internacional y los Incoterms, y su relación con el interés asegurable y la cobertura en el contrato. PRINCIPIA IURIS, (19), 269-324.

AyOĞLU, T. (2014). Some Reflectionson the Sources of Lex Mercatoria. Recuperado de https:// www.trans-lex.org/bibliopdfs/tolga_ayoglu.pdf

Bernitz, U. (2013). Commercial norms and soft law. Scandinavian stuidies in law, (58), 29-44.

Boretto, M. M. (2012). Soft Law. Nuevos enfoques para el desarrollo progresivo del Derecho Internacional de la Propiedad Intelectual. Ars Boni Et Aequi, (2), 81-144.

BOUZA VIDAL, N. (2005). Aspectos actuales de la autonomía de la voluntad en la elección de la jurisdicción y ley aplicables a los contratos internacionales. Recuperado de http://www. ehu.eus/cursosderechointernacionalvitoria/ponencias/pdf/2004/2004_5.pdf

BOyeras SCHUMman, D. (2012). La Compraventa Internacional de Mercaderías la modalidad FOB (Tesis Inédita de Doctorado). Universidad Autónoma de Barcelona, España.

Calderón Marenco, E.A. (2017). Aplicación normativa de la compraventa internacional de mercaderías. Revista de Derecho, (22), 37-60.

Cámara de Comercio Internacional. (2010). Reglas de ICC para el uso de términos comerciales nacionales e internacionales. Barcelona: Apograf S.A. 
Castrillón y Luna, V. (2003). Contratos Mercantiles (2da ed.). Ciudad de México: Porrúa.

CARRASCO GONZÁLEZ, J. (2011). La redacción de los contratos internacionales. Madrid: Colex.

Chavarría Chávez, P. M. (2013). Los Incoterms 2010 y su aplicación en el comercio internacional. Revista Judicial, (108), 202-228.

Chuliá Vicent, E., \& Beltrán Alandete, T. (1995). Aspectos jurídicos de los contratos atípicos. Barcelona: José María Bosch Editor.

Clere, C. (2013). El Derecho Internacional Privado y los procesos globalizadores. Prolegómenos, 16(32), 15-30.

Código Civil de la República de Nicaragua. Publicado en la Gaceta Diario Oficial n. ${ }^{\circ}$ 2148 del 5 de febrero de 1904. Nicaragua.

Comisión de las Naciones Unidas para el Derecho Mercantil Internacional. (2010). Compendio de jurisprudencia basada en la Convención de las Naciones Unidas sobre los Contratos de Compraventa Internacional de Mercaderías. Nueva York: Naciones Unidas.

Cortes Cabrera, B. A. (2014). El Soft law y su aplicación en el derecho comercial. Revista Tribuna Internacional, 3 (6), 55-69.

DÁVALOS FERNÁNDEZ, R. (2003). La regulación jurídica del contrato internacional. Revista Cubana de Derecho, (21), 4-56.

Díaz Bravo, A. (2007). Derecho Mercantil (2da ed.). México: Iure Editores.

DiMATteO, L. A. (2013). Soft law and the principle of fair and equitable decision making in international contract arbitration. Recuperado de http://cjcl.oxfordjournals.org

Espinoza Quintero, L. (2009). Principio de Autonomía de la Voluntad e instrumentos de carácter internacional en el sistema jurídico colombiano. Civilizar ciencias sociales y bumanas, $9(16), 15-40$.

Fernández de la Gándara, L., \& Calvo Caravaca, A. L. (1995). Derecho Mercantil Internacional (2da ed.). Madrid: Editorial Tecnos S.A.

FERNÁNDEZ RoZAS, J. C. (2004). Anuario de Derecho Internacional Privado. Madrid: Iprolex.

FERNÁNDEZ ROZAS, J. C. (2000). El derecho del comercio internacional en el contorno de la globalización. Revista del Colegio de Notarios del Estado de México, (5), 161-230.

FERNÁNDEZ RoZAS, J. C. (2010). Autorregulación y Unificación del Derecho de los Negocios Internacionales. En J. V. GONZÁLEZ GARCía (Dir.), Derecho de la regulación económica (Vol. VIII, pp. 83-138). Madrid: Iustel. 
Fernández Rozas, J. C., Arenas García, R., \& De Miguel Asensio, P. A. (2013). Derecho de los negocios internacionales (4ta ed.). Madrid: Iustel.

FrataloCCHI, A. (1994). Incoterms contratos y comercio exterior. Buenos Aires: Ediciones Macchi.

Galiana SaUra, A. (2016). La expansión del Derecho flexible y su incidencia en la producción normativa. AFD, (XXXII), 297-322.

García CaStillo, T. (s.f.). Lex contractus en los contratos internacionales. Recuperado de https://archivos.juridicas.unam.mx/www/bjv/libros/6/2776/7.pdf

Giménez CorTE, C. (2002). Lex Mercatoria, garantías independientes y coacción extra estatal. Revista de Derecho Internacional y Mercosur, (3), 343-361.

GonzÁlez Martín, N. (2011). Private international law in Latin America: from Hard to Soft law. Anuario mexicano de Derecho Internacional, XI, 393-405.

GonZÁlez Rivera, T. V., \& CASTRILlón y LunA, V. M. (2015). La codificación del derecho mercantil internacional. México: Porrúa.

Herrera Espinoza, J. J., \& GuZmán García, J. (2014). Contratos Civiles y Mercantiles (3ra ed.). Managua: Universidad Centroamericana (UCA).

Huamán Sialer, M. A. (2013). Comentarios a las innovaciones de los Incoterms 2010. LEX, 12, 321-346.

JeREZ RiEsCO, J. L. (2007). Comercio Internacional (3ra ed.). Madrid: ESIC Editorial.

LEIBLE, S. (2011). La importancia de la autonomía conflictual para el futuro del derecho de los contratos internacionales. Cuaderno de Derecho Transnacional, 3 (1), 214-233.

Ley n. ${ }^{\circ}$ 540. Ley de mediación y arbitraje. Publicada en la Gaceta Diario Oficial n. ${ }^{\circ} 122$, del 24 de Junio del 2005. Nicaragua.

Ley n. ${ }^{\circ}$ 902. Código de Procedimiento Civil de la Republica de Nicaragua. Publicada en la Gaceta Diario Oficial n. ${ }^{\circ} 191$, del 9 de Octubre del 2015. Nicaragua.

Marzorati, O. (1993). Derecho de los Negocios Internacionales. Buenos Aires: Astrea.

Mazuelos Bellido, A. (2004). Soft Law: ¿Mucho ruido y pocas nueces? Revista electrónica de estudios internacionales, (8), 1-40.

Medina GonZÁlez, K. A. (2016). La presencia del Soft Law en el derecho administrativo colombiano. Los documentos Conpes como manifestación del Soft Law en Colombia (Tesis inédita de Maestría en Derecho Administrativo).Universidad del Rosario, Bogotá D.C. 
Navarro Pentón, A. G. (2009). Régimen Jurídico de la compraventa internacional de mercaderías en Europa y América latina: ¿Un sistema eficiente? (Tesis Inédita de Doctorado). Universidad de Granada, España.

Ortega GimÉneZ, A. (2008). Contrato de compraventa internacional de mercaderías. Confianza en el Comercio. Madrid: ICEX.

Orúe Cruz, J. R., \& Meza Gutiérrez, M. A. (2009). La mediación y el arbitraje. Managua: Universidad Centroamericana (UCA).

ORTIZ VIDAL, M. D. (2012). Contratación Internacional y espacio jurídico europeo: el principio de proximidad en el Reglamento de Roma I (Tesis Inédita de doctorado). Universidad de Zaragoza, España.

Oviedo AlBÁN, J. (2003). Instituciones jurídicas en procesos de integración y globalización: la formación del contrato de compraventa internacional de mercaderías. Vniversitas, (105), 463-552.

Oviedo AlBÁN, J. (2011). Estudios sobre la compraventa internacional de mercaderías. Aplicaciones jurisprudenciales. Saarbrucken: Editorial Academia Española.

Oviedo Albán, J. (2012). La ley aplicable a los contratos internacionales. Revista colombiana de Derecho Internacional, (21), 117-157.

Pereznieto Castro, L. (1999). Derecho Internacional Privado (7ma ed.). México: Oxford.

Pereznieto Castro, L. (2012). La revolución del Derecho Internacional Privado en el mundo de hoy. Anuario Hispano-Luso-Americano de Derecho Internacional, (21), 401-419.

Pereznieto Castro, L., \& Silva Silva, J. A. (1995). Derecho Internacional Privado. Parte Especial. México: Oxford.

Pereznieto, L. (2013). Tratado de arbitraje comercial internacional mexicano. México: Editorial Limusa.

Rapallini, L. E. (2011). Evolución del "Ius Mercatorum" como fuente del derecho internacional privado del comercio. Anales, (41), 108-116.

REVOREDO DE Mur, D. (1994). La autonomía de la voluntad y la ley aplicable al contrato internacional. Themis, (30), 231-241.

Robleto Arana, C. A. (2010). Arbitraje Comercial en Nicaragua. En J. L. CollanTES GONZÁLEZ (Dir.), Arbitraje comercial internacional en Latinoamérica (págs. 357-451). Perú: Palestra Editores. 
Rodríguez FernándeZ, M. (2010). Los Nuevos Términos Comerciales Internacionales -INCOTERMS- (Versión 2010) y su aplicación en el Derecho Colombiano. Revista e-Mercatoria, 9 (2), 1-73.

RodrígueZ FERnÁNDEZ, M. (2012). Reconocimiento de la Lex Mercatoria como normativa propia y apropiada para el comercio internacional. Revista e-Mercatoria, II (2), 45-84.

Ruiz CASTEllanos, E. (2012). El valor de los Incoterms para precisar el juez del lugar de entrega. Cuadernos de derecho transnacional, 4 (2), 93-122.

Ruiz Castellanos, G. (2016). La nueva Lex Mercatoria. Revista Boliviana de Derecho, (21), 340-351.

SARMiEnTO, D. (2006). La autoridad del Derecho y la naturaleza del Soft law. Cuadernos de Derecho Público, (28), 221-266.

Sierralta Ríos, A. (2001). Palabras linares del derecho internacional del comercio. Revista Jurídica, 4, 37-66.

TOBAR TORRES, J. A. (2012). La nueva Lex Mercatoria o de cuando la realidad supera la ficción. Ataques y defensas de la nueva Lex Mercatoria en el comercio internacional. Pensamiento Jurídico, (34), 239-274.

Del Toro Huerta, M. I. (2006). El fenómeno de Soft law y las nuevas perspectivas del Derecho Internacional. Anuario Mexicano de Derecho Internacional, VI, 513-549.

VernazA, M. J. (2010). El Derecho Mercantil en el contexto transnacional: su relación con el procedimiento de inclusión. Revista Análisis Internacional, (1), 154-170. 